RC

424

F5

UC-NRLF

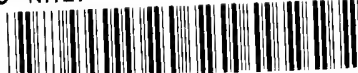

कB 157470

1
0
0
6
0
7 


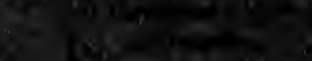




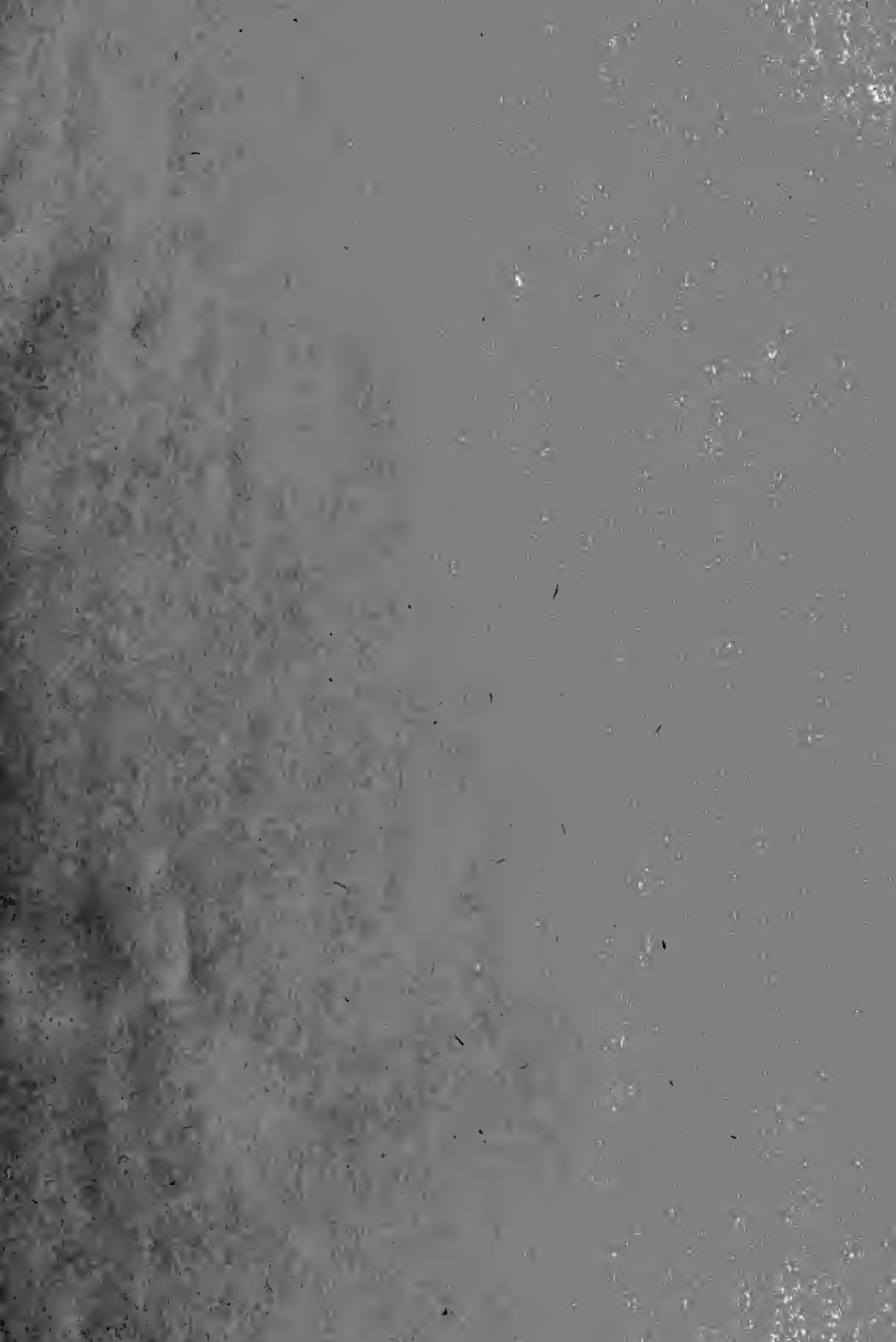





\title{
An Experimental Study of Stuttering
}

\author{
BY \\ JOHN MADISON FLETCHER
}

A DISSERTATION SUBMITTED TO THE FACULTY OF CLARK UNIVERSITY, WORCESTER, MASS. IN PARTIAL FULFILMENT OF THE REQUIREMENTS FOR THE DEGREE OF DOCTOR OF PHILOSOPHY, AND ACCEPTED ON THE RECOMMENDATION OF JOHN WALLACE BAIRD

Reprinted from the American Journal of Psychology April, 1914, Vol. XXV, pp. 201-255 
$F 5$

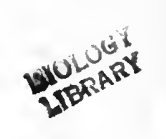

$$
\begin{aligned}
& \because \quad \because \ldots \therefore \\
& \therefore \quad: \therefore \because \therefore \ldots \vdots \therefore .
\end{aligned}
$$




\title{
AN EXPERIMENTAL STUDY OF STUTTERING*
}

\author{
By John Madison Fletcher
}

I. Introduction $\ldots \ldots \ldots \ldots \ldots \ldots \ldots \ldots \ldots \ldots \ldots \ldots \ldots \ldots$ z 201

II. Differentiation and Definition......................... 203

III. Physiological $\ldots \ldots \ldots \ldots \ldots \ldots \ldots \ldots \ldots \ldots \ldots \ldots \ldots, 206$

A. Breathing

a. Historical; b. Subjects; c. Method; d. Results

B. Vocalization

C. Articulation ; b. Results
a. Method; b. Ret

D. Accessory Movements

a. Tics; b. Larynx Movements; c. Miscellaneous Movements

IV. Psycho-physical

224

a. Method; $\dddot{b}$. Results

$\alpha$. Volumetric 'Changes

$\boldsymbol{\beta}$. Changes in Heart-Rate

V. Interpretation

$\gamma$. Galvanic Changes

VI. Psychological

A. Emotions

a. Historical ; b. Results

$\alpha$. Objective

B. Attitudes

$\beta$. Subjective

C. Imagery

D. Attention

E. Responsibility for Aufgabe

F. Psychoanalysis

G. Association

VII. Heredity $\ldots \ldots \ldots \ldots \ldots \ldots \ldots \ldots \ldots \ldots \ldots \ldots \ldots \ldots, \quad \mathbf{2 4 7}$

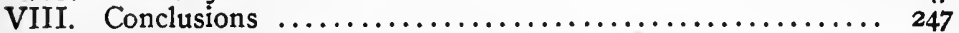

IX: Bïbliography $\ldots \ldots \ldots \ldots \ldots \ldots \ldots \ldots \ldots \ldots \ldots \ldots \ldots, 249$

$\mathrm{X}$. Illustrative Plates $\ldots \ldots \ldots \ldots \ldots \ldots \ldots \ldots \ldots \ldots \ldots \ldots \ldots \ldots \ldots \ldots \ldots$

\section{INTRODUCTION}

The aim of the present thesis is to offer a psychological study of stuttering. This phenomenon is a familiar one but it has received scant notice. The only scientific attention that has been paid to it has come from medical authorities. To the medical fraternity it has been known at least since the

* From the Psychological Laboratory of Clark University. 
days of the Egyptian hieroglyphics (19); but from the medical point of view there is yet no concensus of opinion as to its nature or its treatment.

In reference to the question of incidence no complete statistics are available. On the basis, however, of certain careful estimates it is claimed $(24 ; 38-39)$ that there are approximately a half million speech defectives in the United States. This number is much in excess of the number of the blind, the deaf and dumb, the insane, or the feeble-minded.

Defects of speech are considered to be of more scientific and practical importance in Germany than in the United States. In I886, under Minister of Education von Gossler, the government began activities on behalf of these defectives which have not ceased ( 72 ; I I 2 ff.). Owing to the efforts of the late Dr. A. Gutzmann and his son, Dr. H. Gutzmann, the University of Berlin has been the source from which teachers from the various cities of Europe have secured training for service in the schools. Japan, through the activities of Isawa, has also taken an interest in the problem. In the United States the subject has not received its due scientific attention, while the practical handling of the problem has been almost totally neglected. The victims are not even protected from the charlatans who prey upon them.

It is hoped that the present research will show materials for laboratory use in the study of other problems of general psychology. Advantage could, of course, not be taken of all the ramifications of the problem; nevertheless the clinical cases used in our investigation seemed constantly to afford excellent materials for the study of such topics of general psychological interest as the physiological expression of emotions, the phenomena of inhibition and association, the Aufgabe consciousness, communication, motor co-ordination, voluntary control, attention, etc. Our cases presented a variety of mental conditions that are capable of being repeated at will, conditions which it would be impossible to produce with normal subjects under the usual laboratory conditions. Yet, unlike the insane or the feeble-minded, they possess an intelligence that is normal; and hence they are able to carry out detailed instructions and, if trained, to introspect.

This study, however, is not an attempt to fill a lacuna in any psychological system; it is a frank appropriation of the ordinary methods of laboratory psychology for the study of a problem that seems to be not only a legitimate one for psychology, but also a problem that is of sufficient value to justify the research. It is to be hoped that the practical valie 
that the problem happens to possess will not rob it of its scientific interest for those who hold to the Wundtian notion of the province of pure psychology.1

The study seems to have turned out to be neither exclusively functional nor exclusively structural. It was found necessary to view the phenomenon of stuttering from both aspects, a fact which cannot, of course, be said to make of it a peculiar problem. It also seems to lie somewhat between the fields of normal and abnormal psychology. The subjects are not to be distinguished physically from other people; they are of normal intelligence; their thought processes are logical. In the linking of ideas with the motor processes of speech, however, they are not normal. Arising out of this inability there are to be found certain other associated abnormal conditions that are to be indicated in detail later.

It is desired that the present study will help toward the narrowing of the problem to more convenient proportions. At the present stage it is necessarily comprehensive. In order to reduce it to as narrow a compass as possible the following main problems have been set: $I$. to describe stuttering in terms of its physiological manifestations; 2 . to enumerate and describe the associated mental conditions; and 3. to ascertain, if possible, the part played by these mental states in its causation.

\section{Differentiation and Definition}

In order to avoid confusing stuttering with other forms of speech-defects it will be necessary to adopt a differentiation of the several groups of defects, which for present use will be as follows:

$I$. There is a class of speech-defects resulting from diseases or lesions in those portions of the brain that have to do with the function of speech. This type of defect is known as aphasia. It may be sensory, motor, or associative, according as the region of the brain affected is a receptive, emissive, or associative center. There are many types of this defect, such as aphemia, agraphia, alexia, apraxia, etc. It is an organic disorder due to the degeneration or destruction of brain tissue; it is therefore a form of dementia and hence is a problem for psychiatry rather than for psychology. It will not be taken into account in the present study.

2. Secondly, we have a class of speech defects to be

$1 \mathrm{~W}$. Wundt, Ueber reine und angewandte Psychologie, Psychol. Stud., V. Igog, I-47. 
designated in this connection as "stammering." Schulthess $(24 ; 27)$ in 1830 recognized this as a distinct type of defect, and differentiated it from stuttering by the adoption of the two terms "Stottern" and "Stammeln," which are still in use in Germany. In England and America the terms "stuttering" and "stammering" are used synonymously, with the result that a confusion exists as to the two conditions designated by these terms. To avoid this confusion it has been suggested that technical terms be adopted to designate the two fundamentally different defects. Scripture (127) proposes the terms "hypophonia" and "hyperphonia " to designate stammering and stuttering respectively. "Hypophonia," he says, is " subenergetic phonation," while " hyperphonia" is "superenergetic phonation." This terminology is open to the objection that a differentiation on the basis of the amount of nervous energy employed in speaking does not harmonize with the facts. Stuttering is not merely speaking with an excess of nervous energy; nor does stammering consist merely in speaking with a less amount than normal.

Dr. Makuen has proposed terms that more nearly describe actual conditions (98). For stuttering he proposes the term "dyslalia," or difficult speech; for stammering he proposes the term " pseudolalia," or incorrect speech. However, between the difficulty of securing the general adoption of a new terminology and that of differentiating the terms already in use, the writer has chosen the latter alternative mainly because this does not necessitate a break with the terms in use in the German literature of the subject, which is the most extensive.

Stammering is mispronunciation (107;567-568). The stammerer, unlike the stutterer, can always speak; but his speech is incorrect. This type of defect is found in two forms, namely, (I) the anatomical, and (2) the developmental. The anatomical stammer is due to a malformation of one or more organs of articulation, as the lips, tongue, teeth, hard or soft palate, the nasal or pharyngeal cavities, etc. The developmental stammer has no such physical cause, but is due to the incorrect functioning of the organs of articulation resulting in certain cases from immaturity, as in the "baby talk" of normal children, in whom the condition is not regarded as pathological unless it is prolonged beyond the age of five or six years $(24 ; 22) .^{2}$ The developmental stammer,

2 Colman $(22 ; 454)$ gives an extreme case of "baby talk," or infantile stammer. This child in attempting to say the Lord's Prayer spoke as follows: "Ouë Tade na ah in edde, anno de Di nã, I tidde tah, I du 
which is characteristic of all children at an early age, arises from incomplete perception of vocal sounds and from lack of co-ordination of the muscles of articulation. Lisping is a common form of stammer and consists in the substitution of th sounds for those of $s$ and $z$. The organic type of this defect is due to the shortness of the lingual frenum, or " tongue-tie." 3 Stammering possesses no special psychological interest and will not be considered in the present study.

3. Thirdly, there is a class of defects to be designated as "stuttering." This group is distinguished from the foregoing types mainly by its intermittent character. Stuttering may be called a temporarily appearing inability to begin the pronunciation of a word or syllable. (107;567-568). The capacity of the stutterer to speak seems to be related to certain mental attitudes or states of mind. It is this characteristic that gives the subject its psychological interest.

The evidence for the diagnosis of this defect as primarily mental seems to be accumulating. It was formerly thought to be due to permanent anatomical anomalies, which were amenable to surgical treatment (28). Wedge-shaped portions were cut from the back of the tongue; the hypoglossal nerve, the lingual frenum, and the various extrinsic and intrinsic muscles of the tongue were severed. The tongue was pierced with needles. Cauteries, blisters, and embrocations of petroleum, also inoculations of croton oil were administered. Tincture of rectified alcohol, peppermint oil and chloroform were applied. Wooden wedges were placed between the teeth. Smoking was recommended as a sedative to the vocal cords. The above and various other remedies were devised on the assumption that the difficulty was organic and peripheral (I03). This theory gave place to the notion that, though the defect is not caused by gross anomalies, yet a permanent impairment of the nervous system is present. Kussmaul holds consistently (86) to the view that stuttering is a "spastic co-ordination neurosis." This view is adhered to by many modern writers, especially by those who approach the subject from the medical point of view. Gutzmann $(66 ; 2$ II $)$ holds that every stutterer is neuropathically af-

de di on eet a te e edde, te ut te da ouë dade ded, e didde ouë tetedde a ne ahdin to te tetedde adase ut, ne no te tetate, ninne ut enu, to I ah te nini, ponë e dordy, to edde e edde, Amé."

3 Scripture, in his recent book, Stuttering and Lisping (New York, I9I2, $251 \mathrm{pp}$.), written subsequently to the completion of this paper, has attempted to change the meaning of the term "lisping" to include defects that are usually classified as stammering. See pp. III ff. 
flicted. Scripture claims (I25) that "stuttering is a distinct form of nervous disease . . . ; it can be properly and legally treated only by a physician."

There is, however, a tendency among many medical authorities to lay chief stress upon the mental aspects of the phenomenon, so that the third stage in the progress of its diagnosis may be said to be the one in which mental rather than physical conditions are regarded as primary. Makuen, for example (IO3), says that "many persons stammer (stutter) under certain conditions, largely because they think they will. All their past experiences with speech have combined to confirm them in the thought and it soon becomes a sort of "fixed idea." Langwill (88) believes that "stammering (stuttering) is essentially a functional affection,-a neurosis, the result of the defective working of the complex co-ordinated mechanism concerned in the production of speech, and not a defect of structure. Pathological lesions, therefore, need not be looked for." Gutzmann, in spite of his agreement with Kussmaul, as indicated above (p. 205), says (59): "In the psychology of stuttering we do not find the destruction of any separate fibres or special centers; also the connection between the sensory center and the ideational centers, on the one hand, and the motor center, on the other, are undisturbed. The stutterer simply does not succeed in making the co-ordination from the motor center to the organs well enough to produce the correct mutual functioning."

\section{Physiological}

Physiologically the function of speech involves the co-ordinated action of the three musculatures of (I) breathing, (2) vocalization, and (3) articulation. The aberrations from the normal, that are found in the stutterer's speech, in respect to these three functions, will be taken up in order.

\section{A. Breathing}

a. Historical. Until the methods of observation and palpation had given place to the use of instruments, such as those devised by Marey, Bert, Zwaardemaker, Rousselot and others (59), exact study of these functions was impossible. With some exceptions the earlier studies of breathing were primarily physiological ; and they largely disregarded the mental influences which are taken into account by such studies as those by Mentz (I05) and Zoneff and Meumann (I49). Beforc abnormalities could be indicated it was necessary to 
establish the simpler facts of normal breathing, such as the difference between rest-breathing and breathing during speaking; the relations between thoracic and abdominal breathing, and the like. Halle, who recognizes the influence of mental states on breathing, but who does not attempt a definite correlation, was one of the earliest investigators in this field (73). $\mathrm{He}$ found in the stutterer:

I. Tonic or clonic spasms of the diaphragm in all cases;

2. Psychical alterations of the breathing curve both before and after speaking;

3. Poor economy of breathing ;

4. Attempts at speaking during inspiration;

5. Withholding of the breath after speaking.

Gutzmann (66) originally accepted the findings of Halle but has subsequently changed his opinion. His more recent conclusion $(66 ; 202)$ is that if one would avoid errot one should disregard the influence of mental states on breathing changes altogether. This conclusion, however, seems in turn to be modified by his admission that certain states of mind can have an effect on breathing $(64 ; 16)$. To admit that this is an unsettled question would have an important bearing upon the problem in hand, for, if mental states have no influence on the breathing, stuttering, in so far as it is a disturbance of breathing, must be essentially physiological.

Ten Cate, who was the first to make simultaneous records of thoracic and abdominal breathing-curves, found (I8) that the stutterer is not below the normal in chest expansion; and that, though his expiration period is shorter than the normal, his lung capacity is not below the average. However, he finds that the stutterer's strength of inspiration is greater than that of expiration, which is the reverse of the condition found with the normal speaker. ${ }^{4}$

There are no complete statistics on the number of male and female stutterers; but estimates $(24 ; 362 \mathrm{ff}$.) show that male stutterers preponderate over females in ratios ranging from

4 This last finding would seem to point to some permanent physiological difference that is characteristic of the stutterer. As bearing upon this point it is of interest to quote certain findings mentioned by Greene (44). Greene reports that in cases of forced breathing the strength of inspiration of women is 60 per cent. of that of men, and that of expiration is 66.7 per cent.; that in quiet breathing the strength of the inspiration 66.7 per cent. of that of men, and that of expiration is 63.25 per cent. In all cases, therefore, women are inferior to men in strength of respiration. Yet there are several times as many male stutterers as female. Strength of respiration, therefore, does not seem to be a determining causal factor. 
2:I to IO:I. The male preponderance is much greater in childhood than it is in adulthood; psychological, physiołogical, and sociological differences between the sexes have been pointed out as causes of this preponderance. Differences in breathing-types have been most frequently suggested. That there are sex differences in this regard seems to be granted; it is held, however (37), that such differences are not congenital but are due to the habit of constriction. ${ }^{5}$

b. Subjects. L. R. is a boy fifteen and a half years old, who dropped out of school while in the sixth grade because of his inability to talk. He is in good health, is well grown and well nourished. $\mathrm{He}$ is cheerful, energetic and of normal mentality. He began to stutter at the age of two without any known cause.

$E . B$. is a boy in the eighth grade of the public school, and in spite of his difficulty is making normal progress in his studies. He is healthy and of normal intelligence; his heredity, so far as could be ascertained, was negative for all that could be considered to form a neuropathic basis for his defect.

$F$. $Q$. is a boy 17 years old, of good intelligence, and of pleasing manner. He has had for some years a valvular disorder of the heart. His stuttering was said to have originated in an experience of fright. While playing on the street at the age of six he was accosted by a man who he now thinks must have been insane, and who asked to be directed to a certain place. When the boy attempted to show him the man grasped him by the hand, dragged him into some tall grass and left him. When the man went away the boy escaped and has stuttered since that experience.

$P$. $A$. is a boy 14 years old, normally intelligent, and in good health. He is somewhat rough, indifferent, headstrong, and unreliable. There are no significant facts of heredity, nor is the history of the origin of his defect known.

$A$. $N$. is a young man 22 years of age, of good intelligence, cheerful and friendly. He has good business qualities, and is of good habits. His heredity is negative, and the history of the origin of his defect is unknown. His stuttering is of

5 If permanent breathing-differences, due to constriction, are responsible for the differences in the numbers of male and female stutterers it would seem that where customs of tight-lacing do not exist there should be no such marked differences. As bearing upon this point the writer secured from Japan statistics concerning the prevalence of stuttering among 135,852 boys and 20,637 girls. These statistical data show approximately the same sex differences as are found in other countries. In one prefecture (Yamaguchiken) 5.06 per cent. of the boys are stutterers while only .I6 per cent of the girls stutter. 
severe degree; he is often unable to think of what he is trying to read when stuttering. His mind seems to become befogged under those conditions, and only the memories of feelings and strains are left behind. Even when not attempting to speak he reports that conditions of what appear to be "blank abstraction" come over him.

$W . N$. is a boy 12 years of age, and is the son of a stutterer. The father reports that he himself acquired the defect by imitating a school-mate who stuttered. The boy is regarded by his teacher as being one of the best students in the school. He is in good health. In his stuttering he shows a tonic closing of the lips, the bottom lip pressing against the inner side of his upper teeth, while the chin is in a tremor. In reading, his eyes run ahead to detect the difficult words.

$H$. $A$. is a young man 24 years of age who dropped out of high school on account of his defect. His stuttering began in the fourth grade, and is attributed to the act of imitating a school-mate. He is intelligent, active, competent; he is the son of a physician, and he has excellent training as a machinist. His health is good, and his heridity is negative. His stuttering is worse in conversation than in reading aloud. Talking over the telephone is easier for him than any other form of speech. His stutter movements are strongly suppressed, being confined to the opening and closing of the mouth while the tongue is adhering to the roof of it. Certain consonants give him much difficulty.

$J$. $L$. is a young lady of I8, who is in the third year of the high school. On account of protracted illness, she lost considerable time from school while in the grades. On returning, she was nervously anxious to keep up with her class; and her stuttering began during this period. She reports that when she realizes that she is going to be called upon by her teacher to recite, her heart beats violently. In addition to the stutterer's usual ability to sing she also possesses the ability, not uncommon among stutterers, to speak in public and to participate in amateur theatricals without fear of stuttering. Her stuttering is confined to certain consonants, of which she is in dread. She too runs ahead in her reading to see if difficult letters are ahead of her.

$H$. $D$. is a young man, aged $2 \mathbf{I}$, who began stuttering at the age of 5 by imitating a cousin. $\mathrm{He}$ is in good health, and is physically and mentally vigorous. $\mathrm{He}$ was one of the best debaters in his high school, and was the orator of his class on graduation. Under the stimulus of speaking in public, he does not stutter, while in private conversation he is often 
unable to make himself understood. His stutter movements consist of clinching the jaws and holding them in tonic condition until a violent explosion of the attempted sound takes place. Often his mouth will open widely without effecting the sound desired.

The greater part of the data for the present study was secured from these nine subjects. Many other stutterers were examined, from whom we obtained a limited number of records bearing on certain points.

c. Method. The subjects were seated comfortably in a chair by the side of the table upon which stood the registering instruments; the instruments were hidden from view by a screen. Extraneous noises and other distractions were reduced to a minimum. Time-lines were recorded by means of a Jacquet chronometer. The apparatus was so ar1anged that the experimenter could manipulate it without moving from his seat, or being seen by the subject. For taking the breathing curves two Sumner pneumographs were used, one being placed about the thorax and the other about the abdomen. The registrations were made by Marey tambours on smoked paper attached to the drum of a kymograph. Signal keys connected with the kymograph by means of tambours were used to indicate when the subject was endeavoring to speak. Cards on which were printed various selections of prose and poetry were used as material for speech. When these failed, as they sometimes did, to evoke stuttering, the subject was asked to relate in his own language the substance of something he had read or to give an account of something with which he was known to be familiar. If this failed, strangers were brought into the room and the effects noted.

Attention must be called to the fact that, while in these experiments, methods of registration must remain constant, the stimulus used to provoke stuttering, which is the phenomenon to be studied, cannot remain constant for the obvious reasons that the same stimulus will not produce stuttering in all individuals, and that the same stimulus will not produce constant effects in the same individual.

Strictly speaking the asynergies of vocal utterance would include the disordered action of each musculature taken by itself, and in its relation to the other two musculatures (See p. 206.) In the study of breathing our chief emphasis will be put on the first aspect; whereas in rocalization and articulation it has been necessary for reasons to be indicated later to give chief emphasis to the second aspect. 
d. Results. In general it has been found that stutterers present no permanent peculiarities of breathing unrelated to the function of speaking. This is in accord with the findings of ten Cate (I8) and contrary to those of Gutzmann (66). It must further be said that there are apparently as many varieties of breathing peculiarities among stutterers as there are varieties of stuttering.

Detailed measurements of the breathing-curves were made by using a line drawn in the direction of the movement of the drum to be used as a line of reference from which measurements were made in millemeters to a point midway between the top of the expiration and the bottom of the inspiration curves. These measurements show that the mean variations and the averages are characteristically greater in the breathing-curve during stuttering than during normal speech. The total results of the cases measured are as follows:

$$
\begin{aligned}
& \text { Normal Speaking }\left\{\begin{array}{lll}
\text { I. Av. } & 26.2 \mathrm{~mm} . \\
\text { 2. M. V. } & 3.79 \%
\end{array}\right. \\
& \text { Stuttering } \\
& \left\{\begin{array}{lll}
\text { I. Av. } & 35.6 \mathrm{~mm} . \\
\text { 2. M. V. } & 4.62 "
\end{array}\right.
\end{aligned}
$$

The arhythmic character of breathing is evident from these data.

Many peculiarities of the curves, however, are minute; and do not lend themselves to tabular statement. (See Plates.) The characteristic aberrations may be grouped in three general classes:

\section{Retardations \\ 2. Total misplacements \\ 3. Interruptions}

These are characteristic both of inhalation and of exhalation. I. Retardation means the withholding of inhalation beyond the average time, and the attempt to speak when the lungs are comparatively empty. Exhalation may also be withheld; but this is not so characteristic. Exhalation for the stutterer is apparently more easily performed than inhalation; but it does not always result in the production of sound. Many cases show complete exhalation before the production of sound. In one case exhalation lasted eight seconds yet the attempt at sound was vain. Exhalation is aften interrupted by short, spasmodic inhalations. 2. Total misplacement means the complete breaking up of the natural rhythm 
to the extent that inhalation occurs where exhalation should take place or vice versa. 3. Interruption may occur in two ways; $a$. inhalation may be broken into by exhalation; or $b$. exhalation may be broken into by inhalation. These forms are frequently found; the speech accompanying such breathing is characterized by broken, jerky blurts of speech, appearing frequently in the form of repetition of the initial syllable of a word.

A study of the ratio of the time of inspiration to that of expiration was also attempted with the following results: On computing the averages of the records of each individual, and then the average of these individual averages, it was found that the fraction representing the inspiration-time divided by the expiration-time during normal speaking was .217 sec., whereas in stuttering it was $.535 \mathrm{sec}$; or, otherwise stated, the ratio of inspiration to expiration was found to be more than twice as great in stuttering as in normal speech. Stated in other terms it appears as follows:

Inspiration : expiration : : 217 : 1000 in normal speech;

$$
:: 535 \text { : 1000 " stuttering. }
$$

Since the date of ten Cate's investigations (18), considerable emphasis has been placed upon the temporal relations between the thoracic and the abdominal curves. These relations have been expressed by such general terms as "ahead," "behind," "synchronous," and " anachronous." These terms are found to be inexact for tabulating results for the reason that if. for instance, we take the top of the abdominal curve it may be (I) ahead, (2) behind, (3) synchronous with, or (4) in opposite phase with the top of the thoracic curve if we use the latter as a curve of reference. Similarly, the bottom of the abdominal curve may sustain four relations to the bottom of the thoracic curve. Our tabulated results show that many records are characterized throughout by the fact that, during speaking, the crest of the abdominal curve is behind, while the bottom is ahead; whereas in rest there had been complete synchronism.

The following were compiled from typical cases of breathing curves of stutterers in an attempt to determine whether any definite temporal relationship could be established between the thoracic and the abdominal curves. In each case the thoracic curve is compared with the abdominal. Two points of the thoracic curve are taken, namely, the crest and the trough, and these two points are compared with the two corresponding points on the abdominal curve. Each of these 
TABLE I.

(CREST.) SUBJECT $L . R$.

Showing the temporal relation which the thoracic curve may sustain to the abdominal. The figures in the various columns of the table indicate the number of times the temporal relationship, designated at the top of the column, occurs in the record whose number appears in the extreme left-hand column.

\begin{tabular}{|c|c|c|c|c|c|c|c|c|}
\hline \multirow{2}{*}{$\begin{array}{l}\text { No. OF } \\
\text { RECORD }\end{array}$} & \multicolumn{2}{|c|}{ AHEAD } & \multicolumn{2}{|c|}{ BEHIND } & \multicolumn{2}{|c|}{ SYNCHRONOUS } & \multicolumn{2}{|c|}{ OPPOSITE } \\
\hline & Speaking & Rest & Speaking & Rest & Speaking & Rest & Speaking & Rest \\
\hline 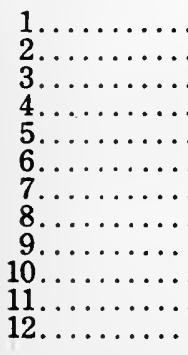 & $\begin{array}{c}\cdots \\
\cdots 3 \\
\cdots \\
\cdots \\
\cdots \\
\cdots \\
\cdots \\
\cdots \\
\cdots\end{array}$ & 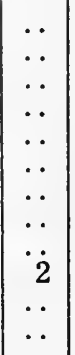 & $\begin{array}{r}13 \\
9 \\
21 \\
8 \\
9 \\
1 \\
6 \\
1 \\
1 \\
4 \\
8 \\
18\end{array}$ & $\begin{array}{r}4 \\
\ddot{1} \\
10 \\
2 \\
\ddot{1} \\
1 \\
1 \\
8 \\
1\end{array}$ & $\begin{array}{r}\cdots \\
2 \\
5 \\
2 \\
6 \\
\cdots \\
3 \\
8 \\
1 \\
13 \\
\cdots \\
25\end{array}$ & \begin{tabular}{|r|}
1 \\
3 \\
$i$ \\
45 \\
6 \\
4 \\
6 \\
36 \\
31 \\
12
\end{tabular} & $\begin{array}{c}1 \\
\ldots \ldots \\
\ldots \ldots \\
\ldots \\
23 \\
7 \\
2 \\
2 \\
\cdots \\
2 \\
2 \\
1\end{array}$ & $\begin{array}{l}\because \\
\because \\
\because \\
2 \\
\therefore \\
\therefore\end{array}$ \\
\hline Totals.... & 4 & 2 & 99 & 28 & 65 & 145 & 40 & $\ldots$ \\
\hline
\end{tabular}

TABLE I.

(Trough.) SUBJEct L. $R$.

Showing the same as Table I above, but using the trough instead of the crest of the thoracic curve as a point of comparison.

\begin{tabular}{|c|c|c|c|c|c|c|c|c|}
\hline \multirow{2}{*}{$\begin{array}{l}\text { No. OF } \\
\text { RECORD }\end{array}$} & \multicolumn{2}{|c|}{ AHEAD } & \multicolumn{2}{|c|}{ BEHIND } & \multicolumn{2}{|c|}{ SYNCHRONOUS } & \multicolumn{2}{|c|}{ OPPOSITE } \\
\hline & Speaking & Rest & Speaking & Rest & Speaking & Rest & Speaking & Rest \\
\hline $\begin{array}{r}1 \ldots \\
2 \ldots \\
3 \ldots \\
4 \ldots \\
5 \ldots \\
6 \ldots \\
7 \ldots \\
8 \ldots \\
9 \ldots \\
10 \ldots \\
11 \ldots \\
12 \ldots\end{array}$ & $\begin{array}{c}1 \\
\cdots \\
6 \\
1 \\
1 \\
\ldots \\
2 \\
2 \\
3 \\
\ldots \\
\cdots \\
10\end{array}$ & $\begin{array}{c}\because \\
\ddot{2} \\
2 \\
. \\
\therefore \\
. \\
. \\
\mathrm{i} 2 \\
\ddot{3}\end{array}$ & $\begin{array}{c}10 \\
8 \\
11 \\
1 \\
24 \\
\ldots \ldots \\
4 \\
2 \\
1 \\
\ldots \\
5 \\
9\end{array}$ & $\begin{array}{c}2 \\
. \\
i \\
. \dot{2} \\
. \\
\ddot{4} \\
\ddot{2} \\
3 \\
.\end{array}$ & $\begin{array}{r}1 \\
3 \\
2 \\
3 \\
2 \\
1 \\
3 \\
4 \\
1 \\
9 \\
1 \\
22\end{array}$ & \begin{tabular}{|c|}
1 \\
1 \\
.. \\
$\because 6$ \\
6 \\
45 \\
5 \\
2 \\
6 \\
19 \\
34 \\
11
\end{tabular} & $\begin{array}{c}1 \\
\ldots . \\
\cdots \\
6 \\
17 \\
\cdots \\
\cdots \\
\cdots \\
4 \\
4 \\
\ldots\end{array}$ & 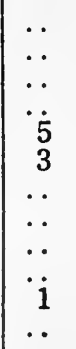 \\
\hline Totals.... & 26 & 19 & 75 & 14 & 62 & 130 & 31 & 9 \\
\hline
\end{tabular}


points on the thoracic curve can sustain four general temporal relations to the corresponding points on the abdominal curve. These relations are, I. ahead, 2 . behind, 3 . synchronous, 4. opposite in phase. The numbers of the record appear in the left hand column. The figures in the other columns of the table indicate the number of times the temporal relation, designated at the top of the column, occurs in the record whose number appears at the left.

TABLE II.

(CREst.) SubJect $F . Q$.

Showing the same as Table I above (page 213) with a different subject.

\begin{tabular}{|c|c|c|c|c|c|c|c|c|}
\hline \multirow{2}{*}{ No. of Record } & \multicolumn{2}{|c|}{ AHEAD } & \multicolumn{2}{|c|}{ BEHIND } & \multicolumn{2}{|c|}{ SYNCHRONOUS } & \multicolumn{2}{|c|}{ OPPOSITE } \\
\hline & Speaking & Rest & Speaking & Rest & Speaking & Rest & Speaking & Rest \\
\hline 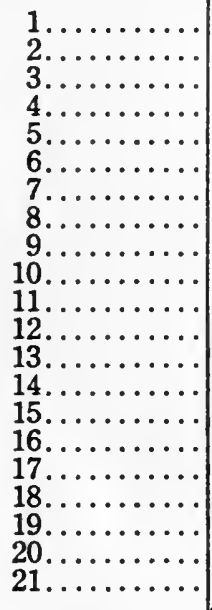 & 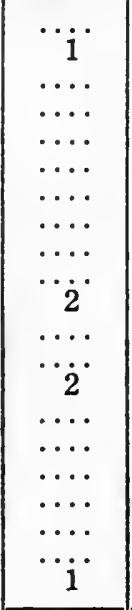 & $\begin{array}{l}i \\
. \\
\therefore \\
\therefore \\
\therefore \\
\therefore \\
\therefore \\
\therefore \\
\therefore \\
\mathrm{i} \\
. \\
\therefore \\
\therefore \\
\therefore \\
\therefore \\
\therefore \\
\end{array}$ & $\begin{array}{r}19 \\
9 \\
11 \\
9 \\
25 \\
9 \\
8 \\
8 \\
4 \\
6 \\
8 \\
6 \\
8 \\
5 \\
5 \\
2 \\
24 \\
13 \\
11 \\
12 \\
12\end{array}$ & $\begin{array}{r}23 \\
15 \\
5 \\
7 \\
14 \\
\because \\
\because \\
\because \\
\because \\
\because \\
1 \\
5 \\
1 \\
\because 3 \\
\because \\
\because \\
2 \\
\because \\
.\end{array}$ & 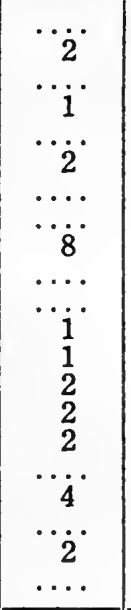 & $\begin{array}{c}\because \\
\because \\
i 6 \\
i i \\
2 \\
1 \\
\because 5 \\
2 \\
4 \\
\because \\
i \\
5 \\
\because \\
i \\
\because \\
\because\end{array}$ & $\begin{array}{c}1 \\
3 \\
\cdots \cdots \\
\cdots \\
1 \\
1 \\
\cdots \cdots \\
\cdots \cdots \\
\cdots \cdots \\
\cdots \cdots \\
\cdots \cdots \\
\cdots \cdots \\
\cdots \\
\cdots \\
\cdots \\
\cdots \\
2 \\
2 \\
1 \\
\cdots \\
\cdots\end{array}$ & 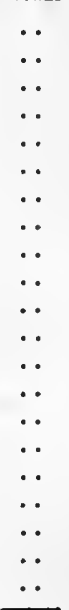 \\
\hline Tc & 6 & 2 & 214 & 91 & 27 & 48 & 15 & . \\
\hline
\end{tabular}

Tables I, II, and III show the following characteristics:

I. The temporal relations of the crest of the two curves do not agree with the temporal relations of the bottom. (Cf., e. g., the crest and trough of Table II.)

2. The character of the breathing curve varies with the individual. (Cf., e. g., the totals of Tables I, II, and III.) 
TABLE $1 \mathrm{I}$.

(Trough.) SubJect $F . Q$.

Showing the same as Table II above, but using the trough instead of the crest of the thoracic curve as a point of comparison.

\begin{tabular}{|c|c|c|c|c|c|c|c|c|}
\hline \multirow{2}{*}{ No. of Record } & \multicolumn{2}{|c|}{ AHEAD } & \multicolumn{2}{|c|}{ BEHIND } & \multicolumn{2}{|c|}{ SYNCHRONOUS } & \multicolumn{2}{|c|}{ OPPOSITE } \\
\hline & Speaking & Rest & Speaking & Rest & Speaking & Rest & Speaking & Rest \\
\hline 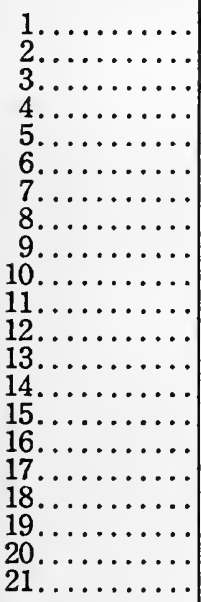 & $\begin{array}{r}5 \\
\cdots \\
\cdots \\
4 \\
2 \\
1 \\
2 \\
7 \\
12 \\
6 \\
4 \\
4 \\
4 \\
10 \\
8 \\
7 \\
22 \\
8 \\
6 \\
8 \\
8\end{array}$ & $\begin{array}{c}\ddot{4} \\
1 \\
\cdots \\
\cdots \\
1 \\
\cdots \\
\ddot{1} \\
\cdots \\
\ddot{2} \\
\cdots \\
\ddot{1} \\
\cdots \\
i \\
\cdots \\
\cdots\end{array}$ & $\begin{array}{c}\cdots \\
\cdots \\
\cdots \\
11 \\
7 \\
3 \\
\cdots \cdots \\
\cdots \\
\cdots \\
\cdots \\
\cdots \\
\cdots \\
\cdots \\
\cdots \\
3 \\
1 \\
4 \\
3\end{array}$ & $\begin{array}{r}12 \\
6 \\
14 \\
12 \\
13 \\
\ldots \\
\ldots \\
\ldots \\
\ddot{1} \\
\ldots \\
\cdots \\
\cdots \\
\cdots \\
\ldots \\
\ldots \\
\ldots\end{array}$ & 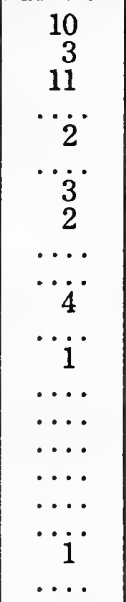 & $\begin{array}{r}7 \\
10 \\
5 \\
10 \\
10 \\
2 \\
1 \\
\ldots \\
\cdots \\
4 \\
3 \\
3 \\
3 \\
\because \\
1 \\
1 \\
i \\
1 \\
3 \\
\cdots \\
\ldots\end{array}$ & 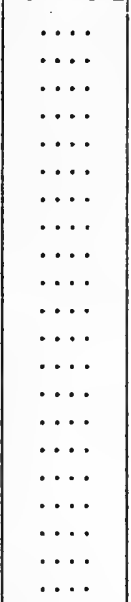 & $\begin{array}{l}\cdots \\
\cdots \\
\cdots \\
\cdots \\
\cdots \\
\cdots \\
\cdots \\
\cdots \\
\cdots \\
\cdots \\
\cdots \\
\cdots \\
\cdots \\
\cdots\end{array}$ \\
\hline Totals..... & 128 & 11 & 49 & 58 & 37 & 64 & $\ldots$ & . \\
\hline
\end{tabular}

3. The individual records of each subject present marked peculiarities at certain times. (Cf., e. g., record 6, Table I, trough.)

The abdominal curve usually shows slighter fluctuations than the thoracic. The former frequently assumes a tonic condition, which has often been described as "cramp" though certain objections have been raised (74) to the use of this term. In many cases the thoracic and abdominal curves tended to approach each other, often to the point of touching; and this would sometimes continue throughout the speaking interval.

With certain subjects (one in particular, $L . R$.) there was found on certain days a complete point-for-point opposition of phase, such as Janet $(8 \mathrm{I} ; 256)$ found to exist in hysterical paralysis of the diaphragm. This phenomenon appeared during the speaking interval only. 
TABLE III.

(Crest.) Subject E. $B$.

Showing the same as Table I above ( page 213), with a different subject.

\begin{tabular}{|c|c|c|c|c|c|c|c|c|}
\hline \multirow{2}{*}{ No. of Record } & \multicolumn{2}{|c|}{ AHEAD } & \multicolumn{2}{|c|}{ BEHIND } & \multicolumn{2}{|c|}{ SYNCHRONOUS } & \multicolumn{2}{|c|}{ OpPosite } \\
\hline & Speaking & Rest & Speaking & Rest & Speaking & Rest & Speaking & Rest \\
\hline $\begin{array}{l}1 \ldots \ldots \\
2 \ldots \ldots \\
3 \ldots \ldots \\
4 \ldots \ldots \\
5 \ldots \ldots \\
6 \ldots \ldots \\
7 \ldots \ldots\end{array}$ & $\begin{array}{l}\cdots \\
\mathrm{i} \\
\cdots \cdots \\
\cdots \cdots \\
\cdots \cdots \\
\cdots \\
\cdots\end{array}$ & $\begin{array}{l}1 \\
\therefore \\
\cdots \\
\cdots \\
\cdots \\
\cdots\end{array}$ & $\begin{array}{l}17 \\
10 \\
17 \\
13 \\
13 \\
15 \\
22\end{array}$ & $\begin{array}{r}24 \\
10 \\
12 \\
11 \\
9 \\
18 \\
23\end{array}$ & $\begin{array}{c}\cdots \\
4 \\
\cdots \\
\cdots \\
6 \\
3 \\
\cdots \\
\cdots\end{array}$ & $\begin{array}{c}\ddot{9} \\
\ddot{5} \\
1 \\
. \\
.\end{array}$ & $\begin{array}{l}\ldots . \\
\cdots \\
\cdots \\
\cdots \\
\cdots \\
\cdots \\
\cdots\end{array}$ & $\begin{array}{l}\cdots \\
\therefore \\
\cdots \\
\therefore \\
\therefore\end{array}$ \\
\hline Totals. . & 1 & 1 & 107 & 107 & 13 & 15 & 1 & . \\
\hline
\end{tabular}

TABLE III.

(Trough.) Subject $E$. $B$.

Showing the same as Table III above, but using the trough instead of the crest of the thoracic curve as a point of comparison.

\begin{tabular}{|c|c|c|c|c|c|c|c|c|}
\hline \multirow{2}{*}{ No. of Record } & \multicolumn{2}{|c|}{ AHEAD } & \multicolumn{2}{|c|}{ BEHIND } & \multicolumn{2}{|c|}{ SYNCHRONOUS } & \multicolumn{2}{|c|}{ OPPOSITE } \\
\hline & Speaking & Rest & Speaking & Rest & Speaking & Rest & Speaking & Rest \\
\hline $\begin{array}{l}1 \ldots \ldots \ldots \\
2 \ldots \ldots \\
3 \ldots \ldots \cdots \\
4 \ldots \ldots \\
5 \ldots \ldots \cdots \\
6 \ldots \ldots \cdots \\
7 \ldots \ldots \ldots\end{array}$ & $\begin{array}{c}\cdots \\
\cdots \\
\cdots \\
\cdots \\
\ddot{5} \\
1\end{array}$ & \begin{tabular}{r}
8 \\
6 \\
18 \\
$\cdots$ \\
\hdashline \\
\\
$\cdots$
\end{tabular} & $\begin{array}{r}12 \\
7 \\
1 \\
13 \\
28 \\
1 \\
16\end{array}$ & $\begin{array}{c}\ddot{9} \\
\dot{10} \\
\ddot{2} \\
\ddot{2}\end{array}$ & $\begin{array}{c}\cdots \\
3 \\
2 \\
\cdots \\
i \\
8 \\
2\end{array}$ & \begin{tabular}{r|}
6 \\
9 \\
3 \\
3 \\
$1 \dot{14}$ \\
1
\end{tabular} & $\begin{array}{l}\ldots \\
\ldots \\
\cdots \\
\cdots \\
\cdots \\
\cdots\end{array}$ & $\begin{array}{l}\cdots \\
\cdots \\
\cdots \\
\cdots \\
\cdots\end{array}$ \\
\hline Totals. & 12 & 36 & 78 & 41 & 16 & 36 & $\ldots$ & . \\
\hline
\end{tabular}

The thoracic seems to be more sensitive to mental disturbance than the abdominal curve. The latter sometimes remains stationary while the thoracic curve shows a uniform upward tendency or else considerable fluctuation.

In many cases breathing disturbances appear before the speaking interval, and also subsequent to it. These afterperiod disturbances have continued as long as eight seconds.

Breathing abnormalities seem to tend toward becoming stereotyped in certain forms for certain individual stutterers. 
These individual peculiarities are numerous and varied in character. They often appear as temporarily adopted expedients to help out in the beginning of speech, just as the stutterer will often be found to start himself speaking by uttering a vowel sound like "ah." Breathing peculiarities of this kind are too numerous and varied to admit of classification. ${ }^{6}$

\section{B. Vocalization}

a. Method. The abnormalities of vocalization do not admit of being studied in isolation from the other physiological processes of speech as well as those of breathing. The aberrations to be studied under this heading will be the asynergies between vocalization and the other processes of speech, particularly that of breathing. This seems to be one of the most characteristic physiological manifestations of stuttering. The writer is not aware of any other attempt to study the relation between breathing and vocalization except by the use of the signal key, which is an inaccurate method.

It was not thought necessary for the present study to secure minute records of the pitch and quality of the voice. It was deemed sufficient to employ an apparatus which would faithfully record when the voice was sounding, and which at the same time would not be responsive to the breath. After the

6 Gutzmann's classification of breathing abnormalities is as follows :

I. Primary disturbances

$a$. Too frequent inspirations; $b$. prior postponement; $c$. clonic and tonic spasms; $d$. temporal opposition of costal and abdominal breathing.

II. Secondary disturbances

a. Spasms of breathing dependent upon spasms of the organs of articulation.

The writer has found examples of all of the above disturbances, and in addition has found disturbances which may be classified as the opposite of I, $a$. and $b$.

Ten Cate ( 18 ) finds:

I. That rest-breathing curves of the stutterer are like those of the normal person.

2. Disturbances of speech-breathing are always present in speech defects.

3. The normal anachronism of speaking-breathing is broken up in case of the stutterer.

4. Inspiration curves are steeper in the stutterer than in the normal individual.

The writer's findings corroborate points $I, 2$, and 4 , but not 3 . The findings reported above have not agreed with the claim that anything like a permanent synchronism between costal and abdominal breathing is to be found in the speech of the stutterer. 
trial of several instruments the Rousselot microphone was found to be best suited to our purpose. The breathing records were made simultaneously with the voice, and on the same kymograph. It was therefore necessary for the drum to turn slowly; hence the stylus connected with the microphone shows only a rapid up-and-down movement during the period of vocalization.

$\checkmark$. Results. It is to be remembered that the characteristic normal rest-breathing curve shows inspirations and expirations of approximately the same length, and that the thoracic and the abdominal curves are approximately synchronous in phase. When normal speech begins, the expiration period is greatly lengthened and the inspiration period is greatly shortened. Also normal speech shows vocalization at the initial point of expiration. Radical departures from these conditions occur in the stutterer's speaking interval. Parallel with the misshapen breathing curves, already discussed, the microphone enables one to locate and measure the periods of vocalization. The aberrations so far noted are of two general kinds: $I$. misplacement, and 2. faulty utilization of voice. Under $I$. will appear frequent cases in which the subject is found to be vocalizing when both his thoracic and abdominal curves indicate inspiration, and still again when his thoracic and abdominal curves are out of phase.

It may almost be said that faulty utilization is invariably present. This lends itself to a sort of quantitative statement. By the selection of a series of type cases from normal and abnormal speaking, the following averages were secured: In the abnormal type, the expiration interval averaged $24.6 \mathrm{sec}-$ onds. The vocalization interval occupied 9 seconds of this,which means that 36.5 per cent. of the expiration interval was utilized in vocalization. The rest of this interval was taken up by aphonic disturbances such as are shown by the pneumograph.

The normal records, on the other hand, showed that of an average expiration interval of 26.8 seconds, 25.6 were utilized in vocalization. Or with normal speaking there appears an efficiency of 90 per cent., as compared with an efficiency of 36.5 per cent. in the case of the abnormal. ${ }^{7}$

7 It may be said that the voice of the stutterer often seems to the auditor to be husky and suppressed,-indicating a tension of the throat muscles, and an improper functioning of the muscles in control of the vocal cords. The husky sounds of the stutterer's voice often gives one the impression of the voice of fear. 


\section{Articulation}

a. Method. By asynergies in articulation will be meant here the disharmonies between the action of the muscles of articulation and those of vocalization. This disharmony is regarded as one of the most important manifestations of stuttering. Since instruments attached to the lips, teeth, etc., of the subject will register the facial contortions which are characteristic of many stutterers, and thus interfere with the study of the actual processes of articulation, the writer has felt the need of an apparatus sufficiently delicate to record the sound of the vocalized consonants and at least to indicate the location on the voice records of the mutes such as the explosives, fricatives, etc., in addition to showing the pitch, intensity and, if possible, the quality of the vocal sounds.

At Stanford University and subsequently at Clark University more than a year was devoted to experiments with the Marbe smoke-ring apparatus in the hope that it could by some improvements be made to serve our purposes. ${ }^{8}$ The attempt to use this apparatus was abandoned for the following reasons: 1 . It can only register pitch,- the amount of deposit on the paper is not a reliable measure of intensity; 2 . the rapid motion of the kymograph was a source of distraction to the subjects and made lengthy records difficult to procure; 3. consonantal sounds cannot be recorded by this means. The flame is inclined to flare out from the drum especially when explosive consonants are pronounced; an important point in the study of the stutterer's voice is thereby lost. ${ }^{\circ}$

8 This apparatus consists of an arrangement by which an acetylene flame, set in motion by the vibrations of the air-waves against a current of gas that passes by a rubber diaphragm in a manner similar to that seen in the Koenig-flame apparatus plays upon the drum of a kymograph which receives deposits of soot (smoke-rings) according to the pitch of the sound.

9 An attempt was made to obviate some of these difficulties by the use of various sorts of diaphragms. One attempt at improvement consisted in the substitution of a telephone disc for the rubber diaphragm. A brass cap was fitted over an ordinary telephone diaphragm in such a way as to form a thin air chamber over it; and a small gas burner was attached to the center of this cap. The gas was introduced over the diaphragm at the side. It was then possible to keep the vibrating body near to and at a constant distance from the flame; and the subject could be kept at a distance from the distractions of the apparatus. Preliminary tests failed to show this to be a satisfactory instrument for the study of the asynergies of articulation. These difficulties are not insuperable, however, and it is planned to renew our attempts to overcome them by the use of instruments like Hensen's phonautograph or Hermann's phonophotograph (I Io; 790). 
b. Results. For reasons already cited the writer cannot here offer results of graphic records similar to those given in our discussion of breathing and vocalization. The findings are therefore to be reported descriptively.

By articulation is meant the molding of vowel sounds into words or syllables by the appropriate positions of the lips, tongue, teeth, hard and soft palate, and the relative openings of the nasal and pharyngeal cavities. Stutterers (without exception so far as the writer knows) can sing. Singing brings vocalization into prominence and reduces articulation to minor importance. This fact has led authorities to conclude that the consonant and not the vowel is the source of the stutterer's difficulties, although it has led another recent writer to draw the very opposite conclusion. ${ }^{10}$ Hunt holds that stutterers have difficulties with vowels as well as with consonants, and so does Mr. Isawa of the Board of Education of Japan, who claims to have found at least one vowel stutterer. We therefore find three distinct theories with reference to this question. One theory holds that consonants alone are the source of the stutterer's difficulty; another that the vowel alone is the source of the difficulties, while a third theory holds that both consonants and vowels are responsible for the defect.

The vowel stutterers are generally described as being unable to leave off certain vowel sounds when once they have begun to sound them. This characterization is, in the opinion of the writer, wrong for two reasons: $I$. The essence of stuttering consists in an inhibition of utterance, and not in an inability to cease utterance (See p. 205); and 2, what seems to be an inability to cease sounding a particular vowel is in reality an inability to combine that vowel with the succeeding consonantal sound to which the stutterer has been looking forward. This claim is in harmony with the well-known law mentioned by Bonnet $(15 ; 52)$ that when a function demands the united harmony of a number of acts, if one of these acts cannot be executed (is inhibited), the others will continue to reproduce themselves until the co-ordination of the movements can finally be secured. This is a familiar occurrence with the stutterer; it is seen most frequently in the repetition of the initial syllable or letter of a word.

10 Bluemel says (I5I; V. I ; I84-I85): “The stammerer (stutterer) rarely has difficulty in singing. But song differs from speech chiefly in the manner in which the vowels are produced; while there is manifestly no radical change in the consonants. The absence of the stammerer's impediment in song indicates, then, that the vowels occasion the difficulty in speech." 
The writers who hold that the consonants are the sources of difficulty for the stutterer have in many cases attempted to make out lists of such consonants. A study of such lists and several attempts to secure them from stutterers have led the writer to conclude that they are not the same for all stutterers, and that they do not remain constant for the individual stutterer. Experiments have moreover shown that if the consonants that are known to be difficult for a certain stutterer are arranged so that they appear in the middle or at the end of a word, instead of at the beginning, the same difficulty is not experienced. Stutterers are also found to be able to whisper without stuttering (the writer has found only one exception to this). The writer has never seen a case of stuttering in the pronunciation of a vowel that was wholly isolated from consonants. He has tested several of his severest cases in this regard by having them read sentences by eliminating all the consonants and sounding only the vowels. If one were compelled to indicate just what point constitutes the difficulty for the stutterer it would doubtless be nearer the facts to say that the asynergy in question consists in the failure of vocalization to be co-ordinated with articulation. This would point to the syllable rather than either the consonant or the vowel. But even so it must be said that the factors that determine the difficulty in all cases seem to be not the nature of the sounds themselves but the mental experiences undergone by the stutterer in his attempts at pronouncing them. Furthermore, meaning can generally not be attached to a single vowel or consonant but it can to a syllable. This, as will be shown later (pp. 240f.), has an important bearing on the rise of stuttering.

\section{Accessory Movements}

Under this heading are grouped the spasmodic radiations of bodily movements which accompany stuttering but which bear no necessary relation to the normal functioning of speech. These radiations include both bodily and facial contortions, which are not merely asynergic but are surplus, unrelated, and illogical in their nature, and for that reason have been called tics.

a. Tics. Stuttering has been defined as a convulsive tic. Bonnet, however, has clearly shown the difference between the two phenomena (15). He finds $\left(I_{5} ; 38\right)$ that tics are often superadded to stuttering, furthermore that stuttering and tics are of common neuropathic stock, and that one may 
become transformed into the other. They possess some marked differences, however. The number of persons, for instance, who are subject to tics is the same for both sexes, a condition which is not true in the case of stuttering. The most frequent age for the appearance of stuttering is from three to five, the next most frequent is from five to ten. Tics appear later, rarely coming before the fifth year. They appear most frequently from six to ten; and the next most frequent time of onset is from eleven to fifteen. There are tics of adolescence, and even of old age, whereas stuttering is thought never to begin after twenty. Stuttering may result from imitation; tics do not. Tics need no provoking cause; they appear apropos of anything or of nothing. Stuttering movements appear only during an attempt to speak. Bonnet thinks ( $5 ; 52 \mathrm{ff}$.) that stutter movements were perhaps primitively adapted to a function. Speech, it is remembered, involves not only the articulatory muscles but mimic muscles as well. In these mimic muscles we may expect compensatory reactions which have the likeness of tics but which lack their essence. The tic is a natural act, a gesture. Stuttering is a progressive attempt to speak, which is thwarted by muscular disorder, dyskinesia, and functional asynergy. In stuttering there is an attempt at motor co-ordination for the purpose of emitting a word or syllable thought of, while the tic is a useless, and involuntary movement which is complete within itself though purposeless.

Bonnet gives $\left(\mathrm{I}_{5} ; 82\right.$ ) the following stigmata of ticqueurs: I. psychopathic predisposition, 2. mental infantalism, 3. feminism, 4. mental degeneration. He believes that stutterers present neuropathic symptoms, but some of these are probably the "result of the tribulations of the life of the stutterer." Mental infantalism, if present at all, is found only during the school-age. After twelve the stutterer makes progress rather above his age. Feminism is thought to appear in young stutterers, and in certain cases also in later life, particularly in those cases that seek solitude. Over against the weaker qualities Bonnet cites cases of "illustrious stutterers" who have been "the indefatigable champions of the cause of religion, art and politics." $\mathrm{He}$ therefore concludes that the stigma of degeneration can not be assigned. By fixation of attention a ticqueur may control or at least decrease the violence of his spasmodic movements. The fixation of attention (See p. 238) by the stutterer decreases the power of control, and increases the violence of the movements.

Von Sarbo (I22) says that verbal tics, such as the use of 
"you know," "you see," "you understand," etc., are especially characteristic of cured stutterers. In the writer's opinion these are not true tics but are expedients which have been purposely adopted, and which are employed to release the initial tension. The stutterer can utter them, apparently for the reason that they mean nothing (See pp. 24of.). It is of interest to know that, whereas all hysterical movements respond to mental influence, tics do not, but are even refractory to hypnosis ( $122 ; 206)$.

The term "spasm" is frequently applied to stitter movements. Pitres $(15 ; 47)$, however, calls attention to the fact that spasms are slow, progressive, and rhythmic contractions, whereas stutter movements are quick, jerky, arhythmic, and explosive.

b. Larynx Movements. Another class of movements, believed by certain investigators to be closely related to stuttering, includes the larynx movements. The writer holds that it is incorrect to assume that because the larynx is a speech organ therefore all its movements, whether normal or abnormal, are essentially related to the function of speech. Whatever superfluous larynx movements are found to characterize the stutterer's speech are, it is held, to be regarded as being as foreign to speech as if they occurred in a remote peripheral organ, as for example, in the foot, where they do often occur, and should be set down as accessory! Gutzmann has given an account of studies made of larynx movements in abnormal speech (67). The methods employed were observation and palpation. The tip of the nose and the ear lobes were held in line and the movements of the larynx were observed while the subject talked or sang. Dermographic marks and Roentgen rays were also employed in obtaining records. Laryngographs were devised by Pilton and improved by Rousselot. Gutzmann himself used the Zwaardemaker apparatus with the Krueger-Wirth Kehltonschreiber for indicating the point at which the vocal sound began.

Gutzmann distinguishes the abnormal movements which begin at the larynx from those which begin elsewhere and extend to the larynx. He believes that if the cramp which closes the glottis comes when the larynx is at its lowest point there is a sudden rise from top to bottom of its position due to the crowding of the expiration air against the closed glottis. Accompanying this condition the abdominal muscles are tensely contracted, and the neck veins are distended, though the neck muscles do not seem to be contracted. In other cases various larynx and neck muscles are involved. Although 
Sikorski (Ibid) claims that the cramped contraction of the neck muscles seldom changes the position of the larynx in any appreciable degree, yet he considers it important to determine which neck muscles participate in these cramps.

Gutzmann concludes his own investigations $(67)$ by saying that the symptomatology of stuttering is almost unlimited and that general conclusions are therefore impossible. This conclusion is in harmony with the findings of the present study on breathing (See p. 229).

c. Miscellaneous Movements. Besides the classified accessory movements already enumerated there are certain illdefined and miscellaneous movements which usually occur in the stutterer's attempt to speak. The writer has observed acts of stamping the feet, of snapping the fingers, of twisting the head, and of opening the mouth; jerky contortions of the face; whistling, pressing the tongue against the roof of the mouth, pressing the lips against the teeth, and pressing the lips together.

\section{PSychophysical}

Under this heading will be noted certain physiological changes which are closely associated with, if not conditioned by, changes of mental states $(138 ; 484)$; although not essentially related to the function of speech, these physiological changes are found to accompany the stutterer's attempt to talk. These are changes of heart-rate, volumetric changes of the blood supply, and galvanic changes.

a. Method. In the study of heart-rate, and of distribution of blood supply, the Lehmann plethysmograph was introduced, in addition to the pneumograph and microphone, already reported. The subject was seated as in the other investigations, and with his right hand inserted in the plethysmograph. The stylus of the plethysmograph tambour was adjusted to a position in vertical line with the others, in order to secure simultaneously $I$. the thoracic breathing curve, 2. the abdominal breathing curve, and the records 3 . of the heart-rate, 4 . of the volumetric changes and 5 . of the voice.

The galvanic records were taken separately from all others. The Deprey d'Arsonval galvanometer was employed. The kind of electrode that proved most suited to our purposes was a large glass jar filled with a solution of sodium chloride. Large copper sheets were placed around the inside of the jar, and to these were soldered the copper wires which led through the batteries and the galvanometer. In the bottom of this jar 
was fixed a wooden handle which was firmly clasped by the subject during the experiment in order to avoid variations in the depth of submergence of the hand. The jars were placed on either side of a comfortable armchair in which the subject sat. An adjustable reading-rack was placed in front of him so as to obviate the necessity of movement. The method of registration was an adaptation of the one used by Radecki ( II6), in which light from the galvanometer mirror was thrown on a graduated scale, which was set at a distance of one meter from the galvanometer. A pointer, suspended from a cord, ran along the scale and could be made to follow the light as it changed its position. The cord which carried the pointer also carried a wire marker, which traced lines horizontally on the smoked paper of a kymograph. If now the deflections of light caused by the turning of the galvanometer mirror were accurately followed, the marks on the kymograph would indicate the exact amount of deflection.

b. Results. a. Volumetric changes. These results admit of general description rather than tabulated statement. $I$. It was observed that there was a marked attention drop where the subject was told to speak or read. The drop was much more decided when the subject was called upon to read, than when he was called upon to speak. This drop occurred in 73 per cent. of the cases. 2. Immediately after the attention drop there begins a rise which usually lasts until the end of the period during which the subject is stuttering. This is found in 90 per cent. of the records. In some cases the rise is extreme, amounting in one case to $4.3 \mathrm{~cm}$. in 43 seconds, and in another to $5 \mathrm{~cm}$. in $3 \mathrm{I}$ seconds. 3. These rises are usually not uniform; they are characterized by many fluctuations, but they have a general upward tendency. In 62 per cent. of the records the general rise is interrupted by irregularities. ${ }^{11}$ 4. Tests were made in which the subjects were asked to imagine themselves in situations in which they would be likely to stutter, and to recall, as vividly as possible, occasions on which they had stuttered. Some of the subjects were

11 The extreme disturbances of breathing, and the various bodily movements which accompany the speech of the stutterer constitute a source of error in the use of the plethysmograph which must constantly and carefully be guarded against. The following phenomena were observed: Sudden bodily movements, especially of the hand, were found to distort the pulse curve and were thus recognized; true plethysmograms are found to be not in phase with the corresponding breathing-curves; the plethysmograms that are affected by breathing disturbances do not show these effects until from 3 to 5 seconds after the disturbance. 
proficient in this, as their introspective reports afterwards showed; but the curves showed no positive changes. In certain cases there was a slight decline. 5. The most important result accruing from this part of the study is the fact that both the amount of the general rise, and the distortions of the plethysmograms are correlated with the degree of the severity of the stuttering (approximately estimated). This fact has been observed by several means. $a$. Records were made of normal individuals while reading; $b$. records were made of stutterers while speaking normally, as for instance, while some one was reading in unison with them; $c$. records were made of cases who could speak better while reading than while talking spontaneously; $d$. finally cases of severe stuttering were compared with less severe cases.

$\beta$. Changes in heart-rate. In tabulating the results of our study of the pulse-rate, three points of measurement were chosen; first, a point in the period just prior to the speaking interval; secondly, a point at the beginning of the speaking interval; thirdly, a point at the close of the speaking interval. The measurements were made at ten-second intervals; and the numbers thus obtained were multiplied by six to give the pulse-rate per minute.

When these results are averaged it is found that the pulserate for the first period is 90.2 ; for the second period, 99.8 ; and for the third period, 98.6. The range of variation of the first period is from 72 to $\mathrm{I} 20$; of the second period it is from 78 to 126; of the third period it is from 72 to 129 . One of the subjects, $W . N$., was only twelve years and seven months old. Lest there might be an error due to his naturally higher heart-rate, the results were again averaged with his figures left out. These averages are as follows: for the first period, 88.9; for the second period, 99.1; and for the third period, 97.2. These investigations continued through more than a year, so that the excitement due to the novelty of laboratory conditions cannot be assigned as an explanation of the findings. Preliminary tests, moreover, were carefully excluded.

From the above results it appears, I. that the average pulserate is above normal in the period anticipatory of speaking; 2 . that the second period is still more above the normal; 3 . that the third period shows a greater average than the first, but less than the second; 4 . that in general, under those conditions that are calculated to produce stuttering, the speech of the stutterer is attended by an abnormal acceleration of the pulse-rate. 
$\boldsymbol{\gamma}$. Galvanic Changes. The experiments here reported were continued through a period of only three months. While they have not gone far beyond the preliminary stage, the results seemed at least to merit mention.

During the progress of these experiments both observation and introspective evidence indicated that a state of excitement was present in the subject when he took his seat in the chair in anticipation of the painful experience of speaking. The galvanometer deflection confirmed this indication. It was therefore found necessary to devise a means of reducing this state of tension until the galvanometer reached a stable point which might be regarded as a zero point. We attempted by various methods, such as the phonograph, free and pleasant conversation, etc., to reduce the subject's tension. During these preliminaries the experimenter was in a position to observe the changes in the galvanometer deflection without the knowledge of the subject. ${ }^{13}$ During this preliminary period of relaxation the deflection tended consistently in one direction (See Plates; see also Table V. p. 228). When the signal to read was given the deflection began to take the opposite direction, in some caess immediately, in other cases after a few seconds. Succeeding most of the speaking records there is again a reversal in the direction of the deflection and a return to the initial direction of the relaxation period. In the midst of one reading period, the subject became suddenly amused and laughed at his own efforts at speaking. This caused a deflection of 15 millimeters in a direction corresponding to that of the initial relaxation period. Some records show continuous deflection in one direction, so that the greatest deflection appears at the end of the record. Other records tend to rise to the extreme position at the central part of the record, and then gradually subside toward the end. Others show deflections that are so sudden that it was impossible to follow accurately with the tracer all the changes that were indicated by the galvanometer mirror. It may be said that the subject in whom this condition was found to exist can read well under favorable conditions. $\mathrm{He}$ is a declaimer in the high school. Only occasionally does he halt at a word which he has seen ahead of him. It was at such places of anticipated trouble that the galvanometer changes

${ }^{13}$ Record 9, Table V (p. 228) shows the effect of failure to reduce this state of excitement. The subject's introspections reported excitement at the beginning; and the slight variation as compared with other records is evident. 
were obtained. The tabulated statement of the extent of these changes can be seen by reference to Table V, below.

\section{TABLE V}

The measurements given in this table are in millimeters; the time of actual changes is recorded in seconds. The measurements are made in three periods as follows: Period I is the preliminary relaxation period; Period II is the interval during which the subject is speaking; while Period III is the final relaxation period after the speaking has ceased. The extent of the maximum variation is found at various points in the speaking period. It is found by measuring the lowest and the highest points in any single, continuous variation that seems extreme. The columns under $a$ indicate the extent of the variation during the periods indicated above them; those under $b$ show the time during which the variation took place.

\begin{tabular}{|c|c|c|c|c|c|c|c|c|c|}
\hline \multirow{2}{*}{ No. of Record } & \multirow{2}{*}{ Subject } & \multicolumn{2}{|c|}{ Period I. } & \multicolumn{2}{|c|}{ Period II. } & \multicolumn{2}{|c|}{ Period III. } & \multicolumn{2}{|c|}{ Maximum } \\
\hline & & $a$ & $b$ & $a$ & $b$ & $a$ & $b$ & $a$ & $b$ \\
\hline 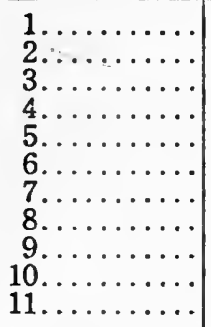 & $\begin{array}{l}A . N \ldots \\
H . A \ldots \\
H . A \ldots \\
A . N \ldots \\
A . N \ldots \\
A . N \ldots \\
A . N \ldots \\
R . T \ldots \\
A . N \ldots \\
D . D \ldots \\
H . A \ldots\end{array}$ & $\begin{array}{r}25 \\
33 \\
\cdots \dot{3} \\
15 \\
\ddot{5} \dot{8} \\
\ddot{12} \\
1 \\
\ldots\end{array}$ & $\begin{array}{l}1 \\
1.5 \\
\dot{1} \\
1 \\
\ddot{4} . \dot{5} \\
\ddot{1} \\
1.5 \\
\ldots\end{array}$ & $\begin{array}{l}47 \\
28 \\
23 \\
11 \\
58 \\
23 \\
65 \\
53 \\
11 \\
21 \\
3\end{array}$ & $\begin{array}{l}7 \\
3.5 \\
2 \\
5 \\
3 \\
3.2 \\
4.6 \\
3.6 \\
5 \\
4.8 \\
2.5\end{array}$ & 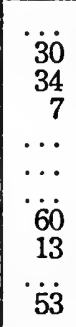 & $\begin{array}{c}1.5 \\
2.1 \\
1.2 \\
\ldots . \\
\ldots \\
\ddot{3} .8 \\
0.8 \\
\ddot{3.6}\end{array}$ & $\begin{array}{r}\ddot{29} \\
\because 64 \\
\ldots \\
\ddot{6} \dot{80} \\
18 \\
31 \\
4\end{array}$ & $\begin{array}{l}1.5 \\
\ddot{1} . \dot{5} \\
\cdots \\
\dot{1} . \dot{5} \\
\ddot{4} \\
3.2 \\
0.7\end{array}$ \\
\hline
\end{tabular}

The findings so far as the present study has gone seem to show $a$. that the stutterer is subject to a period of galvanic disturbance prior to the speaking interval; $b$. that this condition continues in varying degree throughout the interval of stuttering; $c$. that, as with the volumetric changes (See p. 226), the degree of galvanic deflections varies approximately with the severity of the stuttering. ${ }^{\mathbf{1 4}}$

14 Attention should be called to record eleven in Table $V$, in which the stutterer is reading in unison with the experimenter without stuttering. The table shows much slighter variation in this record than in others of the same subject. In record 4 the galvanometer took the direction of relaxation while two stutterers are reading together; 


\section{INTERPRETATION}

It was thought best at the outset to approach the study of stuttering from the physiological side. This was done not without the expectation that these features would on examination warrant generalizations which would possess diagnostic value. The findings from the purely physiological side have, however, forced the conclusion that, taken alone, they do not represent the essential features of the phenomenon. The physiological manifestations of stuttering may be described by such general terms as "incöordinations," "disturbances," "asynergies," etc.; but the description of the essential, uniform or characteristic features has not been possible. The literature of the subject, and the writer's own studies have failed to show precisely what are those physiological manifestations of stuttering that may be called pathognomonic. The physiological accompaniments, as the foregoing results have gone to show, have not been uniform; and they have been found to be sometimes present and sometimes absent in the same individual. Nor has it been possible to establish the existence of a neuropathic diathesis, since it is impossible to know how many neuropathic symptoms are primary or causal, and how many are secondary or sequential.

On the other hand, however, it has been found that the presence of certain states of mind is a constant attendant if not an antecedent of stuttering. The writer's opinion is that these are antecedent and causal; and the indefinite character and almost unlimited variety of the physiological manifestations of stuttering go to show that the latter are symptomatic of conditions which are central and not peripheral. The possibilities of inhibitions, which may be regarded as causing the initial break in the synergic functioning of speech, are enhanced as the source of control approaches the cortical regions on account of the multiplication of the synapses, which Sherrington regards as the seat of inhibition (I30; I92). The remaining portion of this paper will, therefore, be devoted to an attempt to set forth as far as possible those states of mind which are peculiar to the stutterer and which are associated with the function of speech. Since our subjects were not trained psychologists, it was naturally impossible for them to couch their descriptions in technical termirology. No attempt was made to suggest psychological terms

curiously enough, neither one stuttered here, nor had any fear of stuttering. One of the subjects $(A . N$.$) had just previously given$ a record in which the deflection was $64 \mathrm{~mm}$. in the opposite direction. 
to the subjects; and for fear of doing violence to the facts we prefer to present the reports of introspections in their original form.

\section{Psychological A. Emotions}

a. Historical. Hornig ( $77 ; 188)$ holds that, although fear and anxiety aggravate stuttering, they do not cause it, but are merely secondary manifestations. He grants that emotions can and do arise as effects of stuttering; and these same emotions, forming memory complexes which associate themselves with the function of speaking, arise again when speaking is necessary to hinder it by producing the inhibitions, asynergies, etc., already described. So that certain emotions and stuttering are seen to operate in a vicious circle. Wundt holds (146; 65) that speech originated in the expression of emotion, and that movements of expression, of which speech is one, have continued to be closely allied with the emotions.

Gutzmann's position on this question seems difficult to make consistent. He believes that speech belongs to the movements of expression, and that it always exhibits a pleasant or an unpleasant affective tone $(48 ; 385 \mathrm{ff}$.). Particularly does he think (Ibid; Cf. p. 207, above) that breathing and voice, no less than the mimic muscles, are responsive to emotional conditions. Emotions, he says, always change the rhythm and the depth of breathing, the costal breathing being more responsive than the abdominal. The fact that costal breathing is more disturbed in stuttering than abdominal, indicates that emotions play a part here. He holds that the emotions affect the action of the vocal cords; and that they play a prominent part in the speech development of the child. The extreme emotion felt by the deaf-mute child on first learning to utter a word is cited in confirmation of this view. (Ibid., p. 395.) He grants further that the cortical and infracortical regions are more ready to discharge a function when stimulated by emotions; yet he holds that emotions are of no fundamental significance in the causation of stuttering. He believes that the child experiences no intensive depression on account of his stuttering, but that this feeling of depression comes only with maturer years and increase of intelligence. Many stutterers, he says, have no experience that could be called "anxiety before speaking," though in reading, such an experience may appear in certain cases. He claims that he had observed "visual indications" of emotions in one subject just before coming to the letter $k$, which usu- 
ally caused difficulty; but he asserts that the very contrary conditions are also found. His position is $(66 ; 203)$ that it is possible to eliminate emotions from stuttering without altering the defect. ${ }^{15}$

Meumann ( $107 ; 578$ ) holds that every child stammers at some time during his first or second year. When stammering has occurred in the child, the ridicule and mocking of his associates may produce shyness and depression, which are fertile soil for the production of word-anxiety and lack of confidence,-both of which, are symptoms which characterize the stutterer. One seems to be justified in supposing that stuttering never arises in a permanent form except through the intervention of an emotional shock. Mispronunciation, ataxia, lapsus linguae, and Versprechen may occur under certain circumstances in normal individuals; and these are similar to the first stage of stuttering. They are not pathological; but in the young they may readily become so. An American psychologist has given the writer a valuable illustration of this in a personal experience, which is quoted verbatim: "Between the ages of sixteen and eighteen I underwent a dental operation for straightening the teeth. During the time when I was wearing a plate with attachments, my speech was seriously interfered with, and there were many sounds that I was unable to articulate clearly. On an occasion when a number of young people of my own age were present, I attempted to say something about preliminary college examinations; the word "preliminary" caused me great difficulty, and finally, after several attempts, I was obliged to give it up and was greatly embarrassed by the incident. After the removal of the plate I still found myself unable to pronounce the word (preliminary) clearly and met with another embarrassing experience in consequence. I have never since felt safe in attempting to use the word in conversation, for although there is absolutely no physical defect and although I can always pronounce the word without difficulty by pausing a little and making an effort, yet any attempt to use it in conversation is likely to be followed by disaster. In consequence of this I invariably avoid using the word and substitute some other expression." The genesis of stuttering through imitation may, in the writer's opinion, be accounted

15 It seems hardly necessary to remark that Gutzmann's "visual indications" are as inadequate for the detection of physiological manifestations of emotions as were the old methods of observation and palpation for the detection of abnormalities of breathing. The writer takes issue with Gutzmann's position and presents data secured both from physiological registrations, and from introspective reports. 
for on the same principle. Prior to the emotional experience which changes its character and makes it pathological, the imitative stuttering develops an increasingly habitual character. Bonnet reports $(15 ; 55)$ that in the case of some stutterers the mouth is dry and bitter, and the tongue feels as though it were covered with a plaster-like substance. $\mathrm{He}$ finds that some stutterers have veritable trances during which one may observe all the secretory and vaso-motor phenomena that characterize emotions. He has noticed $(15 ; 76)$ that stutterers have less difficulty in speaking when partially intoxicated, because, as they report, they do not feel the same dread under these conditions. He agrees with Merge and Feindall that stuttering is more a matter of the emotions than of the intellect or the will; and with Morel that stuttering can, like obsession, be defined as being at bottom a morbid state of the emotions which expresses itself by motor difficulties, particularly in articulation, arhythmic breathing and vaso-motor disturbances. Stutterers on going to purchase a railroad ticket or an article in a store will often take along a card on which is written the name of their destination or the article wanted. Bonnet $(15 ; 7 \mathrm{I})$ regards this as an unmistakable sign of word-fear, which he thinks arises from the age of 8 to 9 , and is particularly common between $I_{5}$ and 25 .

If Ribot is correct in holding (II8; I7I) that, in certain individuals, emotional memories are possible, while in others they are not, it would seem certain that stutterers belong to the latter class. Titchener claims that two classes of individuals are not to be differentiated in respect to this capacity; but that emotional memories are possible in every individual if the experiences have been sufficiently pronounced. "When a boy is flogged at school," he says (138; $493 \mathrm{ff}$.), "he has, besides the immediate pain of the flogging, all sorts of anticipatory and subsequent stirs of organic sensation,-flutterings, sinkings, chokings, breath-catchings, nauseas. If, when he recalls the flogging in later life, the cortical excitations that underlie his memory-ideas revive the splanchnic and other excitations that constitute the stimuli to organic sensations, then the scene comes back to him with its affective coloring upon it." The stutterer apparently undergoes most, if not all, of the organic sensations enumerated by Titchener. And, upon recall, his painful experiences with attempts at speaking not only bring back memory-ideas with "affective coloring ", but they revive in varying degrees the original organic experiences. 
Appelt ( $1 ; 15$ ) thinks that stuttering "is purely a psychic ailment at whose core stands the dread of speaking." This acts as "an inhibiting agent" to obstruct the speech. ${ }^{16}$

b. Results. Our data have been secured by two methods. $I$. The method of expression ( $138 ; 240 \mathrm{ff}$ ) employs apparatus for the registration of bodily changes during the act of speech by the stutterer. Detailed reports have already been made of the studies of breathing, vaso-motor, pulse, and galvanic changes. They therefore need only to be counted in this connection as objective data in the study. 2. The method of impression has, in the present research, been a difficult one to employ. The difficulty has been due not only to lack of psychological training on the part of the subjects, but to the fact that even on immediate retrospect the stutterer's memory seems vague and hazy as to details. He is often wholly unable to recall what he has read only an instant before. Indistinct memories of his environment and of the bodily sensations connected with his strained efforts at speaking, especially his remembrance of sensations in the throat, the chest, and the abdomen constitute his memory content. In some

16 The part played by the emotions in stuttering has an important analogy in certain hysterical phobias. To Stekel it is more than an analogy, for he contends $(136 ; 300)$ that stuttering is a form of hysteria. The analogy is shown in certain pathological cases, for whose description the writer is indebted to Dr. Edward Cowles of Clark University.

The first is a case of the fear of sweating reported from the McLean Hospital, Waverley, Mass. This subject was frequently distressed when at church or social gatherings by feeling very warm and by excessive perspiration. The hospital report states that "the patient might be playing cards when suddenly he would think that he was going to get hot; he would not sweat for a time perhaps, but the idea that he was going to sweat remained in his mind; he tried to get rid of the thought of sweating; he would become worked up and stirred up, feel a thumping about the heart, a disagreeable sensation in the region of the stomach, and the perspiration would come out."

The second case is that of the fear of nose-bleeding, which is reported in the Russki Medizinski Vestnik, December, Igor. A young man became subject to nose-bleeding, which was generally preceded by vaso-motor disturbances like blushing, blanching, chill and general malaise. If he happened to leave his handkerchief at home, or if he found himself in a place where it would be particularly distressing for his nose to bleed, it would then be most likely to occur. If while attending a lecture at the university the thought of nose-bleeding occurred to him it would bleed. (One can ask, in this connection, whether the fear or the bleeding constituted the obsession. And the same question is also pertinent in the case of stuttering. The writer believes that the weight of evidence, in the present study, shows that the true obsession is mental in the case of stuttering.) 
cases a feeling of complete bodily relaxation quickly supervenes to affect the recall. Two subjects reported that this relaxation was so pronounced that they felt as if they would like to lie down and sleep after a siege of stuttering. One subject reported that while talking his attention was divided between what he wanted to say and what were his chances of saying it without stuttering.

All of our subjects reported that certain letters and collocations of sound looked ominous to them, if they ran their eyes ahead while reading. Synonyms are constantly employed as substitutes for the difficult words.

It was found that if some one read the selection aloud with the stutterer, he was always able to read without stuttering. An attempt was made to obtain data regarding the states of mind under the two situations, in which the stutterer is reading alone, and in which he is reading in unison with some one else. (Graphic records have already been presented, showing that there are differences in physiological processes in the two cases, p. 228, footnote, etc.).

Many subjects, were sure that their feelings were different in the two cases, but were unable to describe the differences. One subject reported that he had " much less fear of failing when reading with some one than when reading alone." When reading with this subject $(A . N$.) the experimenter frequently skipped words, and even whole sentences; yet it was found that the stutterer continued to read through these intervals without stuttering. His introspective reports testified that he felt "secure" while reading alone in these intervals because he knew that if 'he "got stuck" he would be aided and prompted by the experimenter.

Other subjects reported "fear," " anxiety," " uneasiness," "distrust" of themselves, "lack of confidence," "dread," etc: "A feeling of strain" was frequently reported. One subject said that he often felt himself sweating; and many felt the rapid beating of their hearts.

In describing his mental state during stuttering one subject (H. A.) said: "When I am about to speak, I am usually in a somewhat excited state, sometimes more so than at others; when I get into that state I am unable to control myself and I fear'the outcome. I experience an internal trembling and I frequently wonder if I show my excitement to any great extent. I wonder sometimes as to the effects of this on my physical condition. Often I wish that I would somehow vanish when $I$ am in this condition; and at other times I should like to show my ability in other lines, such as 
starting a fight or throwing some object through the window or door; it seems as if that would relieve my state of nervousness."

$H$. A. was found to be able to read fluently a card with whose contents he was familiar, especially if he had read the card before several times. On being asked to reproduce the contents of the card he would stutter severely. When asked to describe his feelings in these two cases he reported that in reading the card he felt "confident" that he could read it as he had done before; that he felt " passive," or " indifferent." When asked to reproduce the contents, he reported that his feelings were changed, that he now felt a "lack of assurance," that he felt himself " getting excited." He would try to prevent this but the effort to do so made him worse. (Cf. the case of phobia, p. 233, footnote). On being asked to give the contents of the card he felt more self-conscious than in reading a familiar selection; he reports that his attention is "very poor" while talking, and that his muscles are very tense, especially those about the throat. Several subjects reported a "feeling of dread" before approaching a stranger to whom they knew they must speak. One subject $(A . N$. said that if he entered a store to make a purchase and found no one there whom he knew, a dread seemed to take hold of him, and often he made his escape without purchasing.

The introspections also showed that after the speaking interval there continues for some seconds a state of excitement which gradually subsides to an indifference-point. This is corroborative of the physiological findings already mentioned (p. 228, and Table V.).

\section{B. Attitudes}

In addition to the more pronounced types of mental disturbances which have been studied by the foregoing methods, there is to be mentioned a group of mental states which it seems best to designate as "attitudes." These states are not so pronounced or intensive as affections or emotions. They do not so fully emerge into consciousness, and hence they do not so readily admit of study; but they nevertheless exercise an important influence on stuttering. Binet (I3) holds that in the attitudes, whether consciously perceived or not, we have the physiological basis of the emotions. Ferrari (36), in agreement with this position, suggests that the autonomic nervous system is the anatomical substrate of the emotional life in general as well as the attitudes mentioned by Binet. 
The assumption of the existence of such attitudes, which differ from emotions perhaps only in degree, seems necessary to account for the extreme physiological effects which sometimes attend what appear to be slight environmental changes. By means of this hypothesis it also seems easier to account for the strength of the morbid associations which characterize stutterers. These attitudes arising from apparently trifling causes are again and again found to determine the stutterer's ability to speak.

It is interesting to note that Geissler's study of consciousness under negative instruction holds that suppression or inhibition of articulation may be either ideational or attitudinal (40). Scripture (129) believes that stuttering is a psychoneurosis, whose essential pathology lies in the disturbance of the stutterer's feeling toward others. This disturbance of the feeling toward one's environment is the phenomenon which is here to be discussed as an attitude. It appears in all degrees from what may be regarded as a primarily intellectual Einstellung to the stage at which it passes into an emotion, such as fear.

In consequence of our lack of subjects trained in introspection, no attempt could be made to analyze these states of mind; hence the data herein submitted are necessarily objective and sometimes merely inferential. Sufficient facts are at hand, however, to make the point clear. The number of these facts could have been extended indefinitely. Appelt (I ; IOI), who was himself a stutterer for many years, says that traveling in a strange country has a marked salutary effect on stuttering; pleasant company has the same effect. $\mathrm{He}$ finds further, a fact often noted, that in the presence of those who are in authority over or in any way superior to the stutterer, his difficulty is more pronounced. This is particularly true if his auditors watch him closely.

It is usually easy for stutterers to talk to children or to animals. The thought that his observer is unacquainted with his difficulty is also helpful to the stutterer (I ; IO2). Nearly all stutterers are able to speak or read without stuttering when alone. Many stutter in conversation but do not stutter in public speaking. The most helpless stutterer studied by the writer had during one summer a position as "spieler" for a side show at a summer resort. This position required him to stand in front of the tent and announce to the passers-by what was to be seen within. He filled this position with success. He stuttered violently in conversation; yet, whenever he was called upon in the laboratory to give his side-show 
"spiel," he could do so without stuttering. Such expedients as changing their style of speaking, as imitating some one's peculiar form of speech, as getting away from their accustomed personality and playing a rôle usually make it possible for the severest stutterer to speak fluently and without difficulty. Pitres (15; 102) tells of a clown who played his rôle perfectly, but who stuttered so badly in private conversation that he could not even say "good morning." Many stuttering actors show no stuttering when on the stage. Masks are found in many cases to relieve stuttering. One of our subjects $(A . N$.$) reports that if he can get into the spirit of$ a poem as he reads it aloud, and can feel its meaning he can read it without stuttering.

Bonnet $(15 ; 77)$ gives an instance of the use of smoked glasses in certain cases for the purpose of giving a feeling of isolation, which was helpful to the subject. Two of the writer's subjects reported that they had less difficulty when speaking in the presence of distracting noises. One subject had a position in an office near a railroad. He found that he could answer the telephone when a train was passing, but otherwise he could not. One subject reported that he could talk better in a store if the counter over which he had to speak was a narrow one than he could if it was a wide one. Stutterers are delicately responsive to the moods, tempers and attitudes of their associates. They seem to "feel the presence" of others quickly and profoundly; and their ability to takk is profoundly influenced by this factor.

\section{Imagery}

It is a well-known phenomenon in psychology that the kinaesthetic images of a certain movement of the body affects the power of voluntary control of that movement (3); and this phenomenon is confirmed by the familiar facts of stuttering, which seems to take place more readily in those organs whose functioning is too complex to admit of direct representation in consciousness. The act of breathing, for instance, can be imaged only partially and more or less abstractly, because the working of the diaphragm can not be imaged and can be controlled only through the lower arch of the abdominal wall. The diaphragm is especially concerned in the breathing abnormalities found in stuttering (66). To co-ordinate vocalization with breathing introduces the function of another complication of muscles which does not admit of direct imaginal representation. The action of the articulatory organs does admit of representation in consciousness, 
and although stuttering speech manifests itself to the eye and to the ear as being primarily a disturbance of articulation, the real asynergy has been shown (p. 2r8, above) to be not merely in the articulatory system, but between this system and others, especially that of vocalization. Whispering, which involves only' the musculatures of breathing and articulation, is usually found to be possible for stutterers.

The organs of speech are neither completely under voluntary control, nor are they exclusively non-voluntary. The abstract act of speech may be called voluntary; but the coordinated action of the muscles which execute the details of speech is non-voluntary. Speech movements, says Hoepfner $(76 ; 268)$, are the first to lose their motor (concrete?) character and to become what must be called abstract (begriffliche) movements. The conscious antecedents of speech movements seem to be general, vague, and except in the articulatory movements, lacking in details. More and more as speech matures is the attention shifted from the physiological process to the content of the thought to be uttered. It is suggested $(32 ; 263)$ that the cortical centers send their impulses to groups of muscles and not to individual muscles. Stuttering, it is to be noted, is not confined to speech. Other groups of muscles which are comparable to the speech muscles in the degree of complexity and in the abstract character of the conscious antecedents of their functioning show this same phenomenon. The writer has had one case of stuttering in deglutition co-existing with stuttering in speech. Bonnet $(15 ; 328)$ reports a case of stuttering connected with defaecation and deglutition. Scripture (I28) and Neumann (II2) report cases of stuttering in writing.

\section{Attention}

Zoneff and Meumann (I49) have shown the effect of attention on the quality of the breathing-curve. They find that in concentrated attention and in the emotions, the thoracic curve is more affected than the abdominal. ( $C f$. the findings reported on p. 215 of this paper.) It has long been recognized that attention plays a part in stuttering. It does not seem, however, to exert its influence only by direct action on the breathing-curve, but rather in more indirect fashion by affecting the morbid associations which themselves are the more direct antecedents of stuttering.

The surgical operations practiced by Dieffenbach (28) are now thought to have owed whatever ameliorative effect they may be credited with to their influence on the attention of the 
subject, or to suggestion. Placing corks or wedges between the teeth, shrugging the shoulders, tapping with the feet, pinching with the fingers, whistling or counting before speaking and numerous similar therapeutic expedients, all of which have been known to be effective in certain cases, seem to owe their efficacy to the fact that they distract the attention of the stutterer from 'his difficulty, and that, in consequence, they afford him a relief from the morbid inhibitions by which his speech is hindered.

Stuttering has frequently been alleviated by the act of writing during speech. 'Many stutterers can speak perfectly while sewing, embroidering, or playing the piano. Others resort to blowing the nose, to scratching the head, or to stroking the mustache before attempting to speak. One subject $(A . N$.) reported that in reading aloud alone, which he could do without stuttering, he often stopped to wonder at his success; and whenever he did so, he at once began to stutter. If alone, he could recover himself; but when any one else was present, he could not. One person of normal speech, a psychologist, reported that there was one word which he had difficulty in using in public speaking. If he used the word without thinking about it, he had no trouble in pronouncing it; but if his attention should fall on it before he got to it he found it prudent to avoid the use of it. This, in intensified form, is the common experience of the stutterer. It has already been noted (p. 22I, above) that the so-called difficult consonants are generally found at the beginning of words. If the stutterer is able to begin a word he is in most cases able to complete it. It is to be noted that in all reading, attention is most keenly concentrated on the first parts of the words. The introduction of rhythm into speech has often had a marked effect on the stutterer's ability to speak. Rhythm, expression, and distraction from fixed ideas constitute the essential principles of treatment according to Scripture (125).

Kussmaul $(85 ; 23)$ stated that stuttering did not exist among the Chinese because of the rhythmic character of their speech. (The I9Io edition of his book, edited by Gutzmann, says that this defect should not exist among the Chinese.) The writer has made sufficient investigation of this topic to justify him in saying that stuttering does exist among the Chinese. Besides numerous private inquiries among persons who have lived in China and among those who have lived near Chinese settlements in America, an attempt was made to ascertain if the Chinese government had taken notice of- 
ficially of the existence of the defect. The government had not taken official action on the question; but Mr. Jung Kwai, Secretary of the Imperial Legation at Washington, D. C., in answer to an inquiry, says that stuttering is by no means unknown in China, and that more than one member of the Legation at Washington is subject to this defect.

Stuttering cannot, therefore, be said to be essentially related to rhythm in speech. The beneficial results derived from introducing rhythm into speech seem to ensue only so long as the innovation is a novelty to the stutterer, and therefore capable of affecting his attention; its therapeutic value is lost when it is a natural characteristic of speech as is the case in the Chinese language.

It is to be noted in conclusion that the wide variety of therapeutic measures employed for the treatment of stuttering could have ameliorative effects only through their influence on some common factor such as attention.

\section{E. Responsibility for Aufgabe}

Associated with the emotions and attitudes already mentioned, the realization of his responsibility for speaking weighs heavily on the stutterer. When a question is put to him, for instance, he feels the necessity to speak. If he does not speak he realizes that unpleasant consequences will follow; the persons with whom he has attempted to speak will become amused, or embarrassed, if not angry. If he were dumb or deaf the situation could be made intelligible to his auditors, but this cannot be done in his case. If he begins to speak and halts, unable to go further, the responsibility to proceed and the heightened feeling of his inability to do so overwhelms him. The realization of that demand, the idea that something is expected of him by way of reaction or reply or communication in consecutive speech, that compulsion arising from a question put directly to him, or a social or business situation in which he may find himself, is the state of mind here meant. If it were necessary to choose some single psychological term in present use to designate this state, that term would be the "Aufgabe consciousness." With the stutterer the realization of the Aufgabe is keen, if not morbid; and, as will appear from the facts, it determines his ability to speak in many instances, and is not confined merely to "coloring" his reactions. As typical of this feeling of the obligation or necessity to speak Bonnet ( $15 ; 69$ ) mentions a stutterer who said that he possessed one good thing which he could use only when he had need of it, namely, speech. One of the writer's 
subjects $(A . N$.) said that he never had any trouble talking nonsense. Another subject $(H . D$.) reported that when called to the telephone he would frequently take the instrument in his hand and while raising it to his mouth would keep saying "hello" without removing the receiver from its hook. The instant he took the receiver off and got into connection with the parties at the other end of the line, and realized a necessity to speak, he became powerless to say anything. Another stutterer reported that he could talk better to his mother than to any one else because she seemed to have the ability to anticipate what he meant to say and could relieve him, at various points, of the necessity of continuing to speak. $H$. $A$. reports that he is helped if his auditor seems indifferent to what he is saying. H. D. states: "I stutter worse when a specific answer is needed, and when a person is looking at me to hear my answer; it is very hard for me to ask for a transfer, upon any particular car-line, such as Lincoln Street, Greendale, etc. Here a particular word must be spoken; there is no opportunity to substitute a word which I could pronounce more easily." Gutzmann has noted that the stutterer finds greater difficulty when a choice of words is impossible $(48 ; 398) . A$. $N$. reports that he is less able to speak if he realizes that some one is watching him; the mere feeling of the presence of another person often renders him unable to speak.

All of our subjects demonstrated their ability to read without stuttering when some one read in unison with them. The writer feels justified in concluding that, under these conditions, the stutterer is not so clearly conscious of the Aufgabe. This relief from the complete responsibility imposed by the Aufgabe, together with the accompanying or consequent changes in emotion-states, already described as characteristic of these situations (pp. 23Iff, above), seems to be an adequate indication of the principle involved.

In certain tests, already described ( $p .225 f$.), the stutterer was asked to recall circumstances under which he had stuttcred or would be very likely to stutter. The results were wholly negative. The reason seems to be that in this case the stutterer was entirely relieved of the task of speaking; and all efforts to revive the physiological processes by mere recall failed.

The assumption of the Aufgabe is only possible when speaking has meaning. Breathing, vocalization and articulation, taken separately or in co-ordination, are possible for the stutterer provided they do not have to coöperate so as to pro- 
duce significant speech. . That singing is possible to the stutterer. seems to be due for the most part to the fact that singing consists chiefly in vocalization (p. 220 , above), and to the fact that singers do not so much feel the responsibility of conveying some meaning to their auditors.

\section{F. Psychoanalysis}

An impetus to the discussion of psychoanalysis in its relation to stuttering was given by Gutzmann (55) in his review of two books on the subject (Eine neue psychologische Behandlungsmethode des Stotterns by Netkatschew; Nervöse Angstzustände und ihre Behandlung by Stekel). In his discussion, Gutzmann adheres $(55 ; 68)$ to his original somatogenic theory of stuttering. He claims that the emotions present are secondary and not primary; and that stuttering is not an anxiety neurosis but an incoördination neurosis due to congenital weakness of the speech apparatus. Stekel (p. 233, footnote) holds to the psychogenic theory of stuttering, and classifies it as a form of hysteria with an anxiety mechanism which originates in sexual traumata.

Laubi had taken the position ( $9 r$ ) that stuttering is due to a mental cause but is dependent upon peculiar diathesis in the form of congenital or acquired structural changes in the nervous system. The fact that it yields to such a variety of treatments warrants him in calling it psychogenic. In a subsequent discussion (90) he cites a case which he claims to have improved by psychoanalysis. Emotional memory-complexes he finds to be the cause of stuttering. The emotional excitability may be either inherited or acquired. In the latter case, if the emotional experience is not originally related to speech it may become so related by a process of transfer (Freudian). For instance, if stuttering should arise in a child as a result of its being bitten by a dog named Schnauz, the emotional complex will be connected with the memory of that name; and the child thereafter will probably be found to stutter on all sch sounds. Gutzmann replies (56) that hypnotic-psychoanalytic methods have not been successful in the treatment of stuttering, that strong mental stimulations may cause stuttering but only under two conditions,-when the excitement is strong, and when the individual is susceptible. Structural modifications are produced in both cases; and these he regards as the essential causes of the defect.

Appelt (I) holds to the Freudian view of stuttering. $\mathrm{He}$ attempts to show (I; IO9) how erotic impressions, which arise 
from fondling in childhood, come under the influence of educational restraints, and may for that reason give rise to intensive inhibitions. The rise of stuttering depends upon the extent of the repression (Verdrängung) and the peculiar diathesis of the individual. He holds that shock, fright or disease never produce stuttering, but that these factors are often regarded as causes by parents and physicians, whereas the real causes lie farther back. Imitation can only cause stuttering where the imitator and the imitated have the same complexes. Freudian identification must be present in the form of an unconscious inference that if the stutterer observed can have such paroxysm of speech, the observer himself may also have them since he possesses the same complexes. Appelt classes stuttering ( 1 ; I33) with the phobias and the obsessions. The physical and mental symptoms of stuttering are "merely the projections of the conflicts which have accumulated in the emotional complex. All paroxysms of stammering (stuttering) are produced by energy which is supplied by suppressed libido."17

The writer is unable to accept the Freudian interpretation of stuttering for the following reasons:

$I$. He agrees with Gutzmann that the employment of the method of psychoanalysis has not been sufficiently successful in the treatment of stuttering to warrant its adoption. Treatments based upon other diagnoses have been much more successful. Mere suggestion, wholly aside from the Freudian hypothesis, seems sufficient to explain the results of the use of the method.

2. Emotional memory-complexes in children may be accounted for without reference to the sexual element from the facts, $a$, that speech in general possesses a genetically emotional character; $b$, that speech in the child is usually attended by stronger feelings and emotions than in the case of the adult; $c$, that morbid conditions easily arise with the child from various causes, such as embarrassment resulting from errors of speech, from criticism, from ridicule or from mockery; $d$, that the child at an early age is compelled to use the complex musculatures of speech without the possibility of developing slowly by the use first of the more fundamental and then the accessory, according to the law for the best development of motor co-ordination; $e$, that emotional memory-complexes may arise from nervous shocks other than sexual.

17 Scripture (Stuttering and Lisping, New York, 1912) seems at the present to accept the Freudian view of stuttering. 
3. There seems to be no adequate reason for supposing that only those emotional complexes which have a sexual origin can cause stuttering. Such a theory of stuttering, when one attempts to apply it, is found to necessitate the introduction of another theory, namely, that of transfer, to explain how sexual traumata are switched into the function of speech.

4. The hysterical conditions supposed to be caused by the suppression of the sexual complexes seem to be more characteristic of females than of males, while stuttering is many times more common in males than in females. (See pp. 207f.)

\section{G. Association}

In a former section (p. 22I) it was shown that the difficulty encountered by the stutterer in the pronouncing of certain letters is determined, not by the nature of the letters themselves, but by the experiences associated in the stutterer's mind with the use of those letters. One of the subjects, $W . N$., acquired a persistent tendency to stutter in pronouncing a particular word in consequence of one unsuccessful attempt to give a number while going through his regular test in counting from one to twenty. To instruct him to be on his guard as he came to that number seemed each time to furnish a positive suggestion to stutter.

Bonnet $(15 ; 75)$ cites a similar case: A soldier had answered "present" for three months without stuttering. One day when the roll was called by a sergeant who had punished him the day before, he was unable to answer "present"; and he continued to stutter only when that particular officer called the roll. Bonnet holds that any case of stuttering which originates in reading will remain a case of reading-stuttering. The same phenomenon appears in reciting, in telephoning, etc. This may be called "associative stuttering." It is not, however, to be construed as meaning a new variety of stuttering. If we extend the notion of association beyond the range of conscious ideas and make it include a wider range of physiological processes, all stuttering may be said to be associative. As a descriptive term there appears no objection to regarding stuttering as an "associative neurosis" provided one agrees with Donley (33) that this does not represent a "disease entity," or a "disease form," but only a "functional variation." The rise of vaso-motor, secreto- 
motor, and other physiological changes through association, when there is no conscious recall, is not peculiar to stutterers alone. ${ }^{18}$

Langfeld's studies (87) show that in association experiments, where the reagent is instructed not to respond with the name of the presented picture, the negative Aufgabe may produce a "locking of the muscles of the organs of speech," which sometimes occurs without "consciousness of the instruction or of a judgment." He finds that suppression may be present in various forms, from a voluntary act to a purely automatic reaction. In the case of the stutterer, the Aufgabe consciousness involves no explicit negative instruction but the complex of associations which is antagonistic to the positive instructions is effective in accomplishing the inhibition.

Hoepfner (76) holds that stuttering is an associative aphasia. This term is objectionable only in that it generally implies an organic lesion or a structural malformation.

The mechanization of associations and the fixing of neural paths is unquestionably present in stuttering; and, in so far, stuttering falls within the category of habit, unless we choose to limit the notion of habit to the modifications produced by repeated performance. ${ }^{19}$

Stuttering arising from shock, from disease, and from imitation (which in some cases may be repeated very few times), is obviously not due to repeated performance. Just how being bitten by a dog $(53 ; 92)$ can produce stuttering in the same fashion in which habits are acquired is not easy to see; but it is possible that, in such a case, speech may be regarded as the natural mode of defence through which the nervous shock found expression, and in doing so fixed the line of nervous discharge as effectively as repeated performance would. In such a case the whole anxiety neurosis or association complex must become switched off into the function of speech, so that it no longer attaches itself to the particular experience of being bitten by a dog, which was the original cause of the

18 Betz (II; $273 \mathrm{ff}$.) reports an incident which seems to have a bearing here: One day, on a street-car, he saw a fellow passenger light a cigar and settle back in his seat for a comfortable smoke. But a sudden jolt of the car dislodged the cigar and threw it upon the floor: and the ludicrousness of the incident caused Betz to smile. A few days later he saw a stranger whom he felt he had seen before. In his prolonged effort to "place" the stranger he found himself smiling; and the reproduced smile proved to be the medium through which the street-car incident and the smoker's face were finally recalled.

${ }^{19} \mathrm{Cf}$. Baldwin and Stout's discussion of habit in Baldwin's Dictionary. 
shock, but to the general function of speech. It would, then, no longer be a general condition of anxiety but would be connected only with the act of speaking.

The part played by the element of conation in stuttering also seems to differentiate it from habit as commonly understood. In the first place stuttering in all of its pathological aspects can scarcely constitute the goal of voluntary effort. The imitation of stutter movements, to be sure, may be voluntary and as such may obey the laws of the acquisition of habit, but when this mere imitation of the stutter movements gets to be actual stuttering a new condition arises in which the individual becomes a victim not merely of the motor habit acquired through a few repetitions but a victim rather of the associated mental conditions. To illustrate, the writer has the history of a case in which a child became a stutterer by attempting to show his mother how a clown had stuttered in a circus. If stuttering were a mere motor habit it is evident that the clown would have been much more of a stutterer than the child by reason of the constant repetition of stuttering in his daily performances.

Again, just as "repeated performance" is not essential to the rise of stuttering, and when carried out does not always result in stuttering, so it is found that "cures" are not always effected in the same fashion in which one motor habit, for instance, is supplanted by another. Many stutterers, for instance, are cited.(125, 126, 127) who ceased to stutter almost immediately when shown how to introduce some new variation, such as rhythm, into their speech.

It is to be noted further that if stutter movements were simply motor habits like peculiarities of hand-writing, for instance, they would be expected to occur with equal if not increased facility in the absence of attention. It has already been shown (p. 239) that stuttering tends to disappear when the stutterer's attention is distracted from his speech.

From the above consilerations the writer has concluded that the term "habit" does not wholly describe the true conditions of stuttering, and that if the term is to be employed it should be used to designate rather the mental states which, it is held, constitute the essential pre-conditions of stuttering. But it is to be borne in mind that these mental states do not obey the law of habit by coming into being through volitional conation, nor are they marked by a progressive decrease of this volitional element until the habit has become fixed. In- 
stead they come involuntarily and there is no evidence against the assumption that they continue to be opposed in equal degree by the will of the stutterer.

\section{HEREDITY}

The study of heredity in its relation to stuttering would not come within the scope of an experimental attack upon the problem, such as the writer has undertaken. It will, therefore, be mentioned only in so far as it has a bearing on the conclusions reached in the present study. The facts so far known seem only to warrant opinions rather than definite conclusions regarding the inheritance of the defect; and the opinions differ. Gutzmann believes that stuttering is due to inherited peculiarities of structure $(55,6 \mathrm{r}, 122,180)$; and this view is accepted by writers less well known (I5;2I). McReady (97) classifies stuttering with amusia, and states that it is due to "biologic variations" in the brain centers. This view illustrates the futility of undertaking to base stuttering on physical stigmata. A distinguishing characteristic of stuttering is its intermittence (p. 205); if persons afflicted with amusia were found to possess the power of tonal discrimination when in certain states of mind and not when in others there would be some grounds for classifying the two defects together.

One cannot but admit the possibility and even probability that a favorable neuropathic diathesis is present in the stutterer; but it is acknowledged that this does not explain why many persons of neuropathic diathesis never stutter. The causation of stuttering by imitation also seems out of accord with the structural explanation of the defect. To establish the hereditary character of stuttering one must find a stutterer who is descended from stuttering ancestors, and who has never observed stuttering in others, which is obviously a very difficult thing to do. One of the writer's subjects ( $W . N$. ) was the son of a stutterer; and the father reported that he himself had acquired the defect by imitating a school-mate. To assert that the son inherited the father's acquired character would be to cut the knot of the whole inheritance problem at once. Such errors as this, it is feared, have crept into statistical reports on the problem of heredity in stuttering.

\section{Conclusions}

1. The motor manifestations of stuttering are found to consist of asynergies in the functioning of the three musculatures of speech,-breathing, vocalization, and articulation. 
2. Accompanying these asynergies there are also to be found tonic and clonic conditions of other muscles which are not involved in normal speech. These accessory movements tend to become stereotyped in each individual.

3. Stutterers are found to differ widely in type of asynergy, and particularly in accessory movements. It is, therefore, impossible to assert that any form of breathing, of articulation, or of vocalization constitutes the essence of stuttering.

4. Besides the motor manifestations of stuttering there are other accompanying conditions which consist in disturbances of pulse-rate, and of blood distribution, and in psycho-galvanic variations; these changes appear before, during, and after the speaking interval. The intensity of these manifestations is found to vary approximately with the severity of the stuttering.

5. The essential condition of the rise of stuttering seems to be a complex state of mind, which should be classified generically as feeling, in the wider sense of that term (138; 227). It is to be noted, however, that the quality rather than the intensity of these feeling states governs the rise of the defect. Certain forms of excitement, such as that incident to speaking in public, for example, caused stuttering to disappear entirely in over fifty per cent. of our cases.

6. In general the feelings that tend toward inhibition or depression, such as fear, anxiety, or dread, or shame or embarrassment, are the ones that are most likely to be the precursors of stuttering. Probably all of these attendant mental states operate in a vicious circle in that they act as both cause and effect. The writer is of the opinion that in general the permanent condition of nervousness that is thought to be characteristic of stutterers should be regarded as effect rather than cause.

7. The states of feeling that have to do with the production of stuttering vary in degree from strong emotions to mere attitudes or moods. These latter are often so slight in degree that it is difficult for the subject to report their presence, and yet by the logical "method of difference" it seems necessary to consider their presence as a causal factor.

8. In addition to states of feeling, stuttering seems to be affected by the quality of mental imagery, by attention, and by association. All movements that, like those of speech, are incapable of clear and detailed imaginal representation in consciousness are, in the same way as speech, liable to functional disorders that are analogous to stuttering. When the stutterer's attention can be distracted from his speech his stut- 
tering generally ceases. The affective and emotional experiences associated with the pronunciation of sounds, rather than the nature of the sounds themselves, determine the rise of stuttering.

9. Stuttering, therefore, seems to be essentially a mental phenomenon in the sense that it is due to and dependent upon certain variations in mental state. Hence the study of stuttering becomes a specifically psychological problem; and it seems evident that a detailed analysis of all the various aspects of the phenomena of stuttering will furnish important contributions to general psychology.

\section{Bibliography}

- I. Appelt, Alfred. Stammering and Its Permanent Cure. London, I9I I, 234 pp.

2. Auerbach, S. Traumatische Neurose und Sprachstörungen. Monats. f. Psychiat. u. Neurol. XVII., 1905, 84-92.

3. BaIR, J. H. The Practice Curve. A Study in the Formation of Habits. Psychol. Rev. Mon. Sup., No. 19, 1902, 70 p.

4. BARBER, I. Sprachstörungen des Kindes. Artz als Erzieher, V., 1909, 73-74.

5. Barth, E. Neuere Ansichten über Stottern, Stammeln, Poltern, und Hörstummheit, Wien. klin. Rundschau, XVIII., 1904, 697-724.

6. Bayerthal, J. Ueber Gehirn und Sprachstörungen bei Schulkindern. Zeits. $f$. Kinderforschung, XVI., I9I0, I-8.

7. Bennke, Emil. On Stammering, Cleft Palate, and Lisping. London, $1907,89 \mathrm{pp}$.

8. Bell, Alexander Graham. Lectures upon the Mechanism of Speech. New York, 1906. I29 pp.

9. Berger, Hans. Ueber die körperlichen Aüsserungen psychischer Zustände. Jena, 1907, 216 pp.

to. Berillon, M. Le traitement psychologique du begaiement mental et de la timidité. Rev. de l'hypnot. et psychol.-phys. XVIII., 1903-4. I72-174.

I1. Betz, W. Vorstellung und Einstellung. Archiv f. d. ges Psychol., XVII., 19I0, 273-274.

12. Biluings, M. L. and Shepard, J. F. The Change of Heart Rate with Attention. Psychol. Rev. XVII., I910, 217-228.

13. Binet, A. Qu'est-ce qu'une émotion? Année psychol., XVII., I9I1. I-47.

14. Binet, A., and Henri, V. Les actions d'arret dans les phénomènes de la parole. Rev. phil., XXXVII., I894, 608-620.

15. Bonnet, LouIs A. L. Etude critique sur la parenté morbide du begaiement avec les tics et les crampes fonctionelles. Bordeaux, 1906. $168 \mathrm{pp}$.

I6. Bramwell, B. Functional Speech Affection Cured by the Milk Isolation Plan of Treatment. Clin. Studies, IV, 1905-6, 77-79.

17. BrILl, A. A. The Anxiety Neuroses. Jour. Abn. Psychol., V., 19I0, $57-68$. 
18. TEN CATE, M. J. Ueber die Untersuchung der Athmungsbewegung bei Sprachfehlern. Monats. f. Sprachheilkunde, XII., I902, 247-259; 32I-34I.

19. ChERVIN, ARTHUR. Begaiement et autres maladies fonctionelles de la parole. Paris, I90I, $551 \mathrm{pp}$.

20. Conn, R. Pathologie und Therapie der Sprachanomalien. Wien, I886, 246 pp.

21. Collins, J. The Faculty of Speech. New York, 1898, 432 pp.

- 22. Colman, U. S. Impediments of Speech. Allbutt's System of Medicine, VII., 448-456.

23. Colombat, Marc. Traité de tous les vices de la parole et en particulier $d u$ begaiement. Paris, I840, $558 \mathrm{pp}$.

24. Conradi, Edward. Psychology and Pathology of Speech Development in the Child. Ped. Sem., XI., 1904, 327-380.

25. Dattner, B. Eine psychoanalytische Studie an einem Stotterer. Centralbl. $f$. Psychoanalyse, II., I9I I, No. I, 18-26.

26. Denhard, Rudolf. Das Stottern; eine Psychose. Leipzig, r890, $298 \mathrm{pp}$.

27. - Vom Stottern. Deutsche Med. Zeitung, XXIX., Ig08, $93 \mathrm{ff}$.

28. DiefFenbach, J. F. Die Heilung des Stotterns durch eine neue chirurgische Operation. Berlin, 1841, $35 \mathrm{p}$.

29. DitTrich, OtTMAR. Grundzüge der Sprachpsychologie. Halle, I904, $786 \mathrm{pp}$.

30. - - Bilderatlas zum ersten Bande der Grundzüge der Sprachpsychologie. Halle, I903, 95 pp.

31. DodGe, RAYmond. Die motorischen Wortvorstellungen. Halle, I896, $78 \mathrm{pp}$.

32. Donaldson, Henry Herrert. The Grozeth of the Brain. London, I895, $374 \mathrm{pp}$.

33. Donley, John E. A Further Study of Association Neuroses. Jour. Abn. Psychol., II., I907-8, 45-57.

34. Dunlap, K. Galvanometric Deflection with Electrode Applied to the Animal Body. Psychol. Bull. VII., I910, I74-I77.

35. Duprot, G. L. Les troubles de la parole chez l'enfant. Man. gen. de l'instruction primaire, No. I8, I900, 277-279.

36. Ferrari, G. C. Le emozioni e la vita del subcosciente. Rivista di psicologia, VIII., I9I2, 97-I 18.

37. Fitz, G. W. A Study of Types of Respiratory Movements. Jour. Exper. Med., I., I896, 677-692.

38. Foster, Michael. A Text-Book of Physiology. Sixth Ed. New York, I893

39. Franz, Shepherd Ivory. On the Functions of the Cerebrum; the Frontal Lobes. Archives of Psychology, I., No. 2, I907. $64 \mathrm{pp}$.

40. Geissler, L. R. Consciousness under Negative Instruction. Amer. Jour. Psychol., XXIII., 1912, 183-213.

4I. Girard, G. M. De l'anxiété. (Thèse méd.) Bordeaux, I902, $86 \mathrm{pp}$.

42. GLORIEUX, M. Tic hystérique avec hypertrophie musculaire. Brux, 1906. I20 pp.

43. GodTfRing, Отto. Unsere stotternden und stammelden Kinder. Kiel, I906. 23 pp.

44. Grenne, E. The Preponderance of Male Stammerers over Females. N. Y. Med. Jour. LXXIII., I901. 635-638.

45. Gregoire, J. Les vices de la parole. Paris, igo8. I I9 pp. 
46. Grossard, M. Begaiement et végétations adénoides. Bull. de lar., otol. et rhin., VI., 1903. 261-266.

47. GRÜnbaum, Ferdinand. Erklärung des Stotterns, dessen Heilung und Verhütung. Leipzig, I897. 63 pp.

48. Gutzmann, Hermann. Das Verhältnis der Affekte zu den Sprachstörungen. Zeits. f. klin. Med. LVII., 1905. 385-400.

49. - Ueber Sprachstörungen bei Neurasthenikern. Verhandl. $d$. Kong. $f$. innere Med. XXI., rgor. 518-522.

5o. _- Ueber Untersuchung und Behandlung der durch Gaumen- oder Zahndefekte entstehenden Sprachstörungen Deutsche Zahnartal. Wochenschr. VIII., 1905. 186-209.

51. - Die Sprachstörungen als Gegenstand des klinischen Unterrichts. Leipzig, r905. 39 pp.

52. — - Stimmbildung und Stimmpflege. Wiesbaden, 1906 I6I pp.

53. - Sprachstörungen und Sprachheilkunde. Berlin, Igo8. I89 pp.

54. —_ Grundzüge der Behandlung der nervösen Sprachstörungen. Deutsche Med. Wochenschr., XXXII., 1906. 612-617.

55. - - Ueber psychogenen Sprachstörungen. Monats. $f$. Sprachheilkunde, XX., 1910. 93-94; 97-II7.

56. —_. Nochmals die psychogenen Sprachstörungen. Monats. f. Sprachheilkunde, XX., 1910. 204-2 10; 241-247.

57. - - Das Stottern. Frankfurt a. M., 1898. 460 pp.

58. — - Die soziale Bedeutung der Sprachstörungen. Klin. Jahrb. XII., 1904. 295-364.

59. — - - Ueber die neueren Fortschritte in der Untersuchung und Behandlung der Sprachstörungen. Zeits. f. diact. u. phys. Therapie. VIII., 1904-5. $53 \mathrm{r}-604$.

6o. - - Sur le symptomatologie et le traitement de l'aphonie spasmodique et d'autres troubles phonateurs d'origine. Archiv internat. de laryng. XXI., 1906. 689-723.

61. — - Ueber die Bedeutung der Erblichkeit für die Entstehung von Sprachstörungen. Zeits. f. aertzl. Fortbild. IV, I907. $481-489$.

62. - Des Kindes Sprache und Sprachfehler. Leipzig, I894, 264 pp.

63. - Die Heilkurse für Stotterenden. Monats. f. Sprachheilkunde. XVII., 1907. 386-391.

64. - Physiologie der Stimme und Sprache. Braunschweig, I909. $208 \mathrm{pp}$.

65. - Stimmbildung und Stimmpflege. Wiesbaden, 1906. I6r pp.

66. Die Atembewegung in ihrer Beziehung zu den Sprachstörungen. Monats. f. Sprachheilkunde. XVIII., I908. 'r79-201.

67. U_ Ueber Stellung und Bewegung des Kehlkopfes bei normalen und pathologischen Sprachvorgängen. Beitr. z. Anat. Physiol. Path. u. Ther. des Ohres, usw. I., 1908. 89-133.

68. - Ueber die spastischen Stimmstörungen und ihre Behandlung. Med. Bl.. XXVIII. 1905. $543 \mathrm{ff}$.

69. L - Sprachstörungen und Rhinó-Laryngologie. Zeits. f. Laryngologie, I., 1908. 97-99.

7o. - Ueber die Bedeutung des Vibrationsgefühls für die Stimmbildung Taubstummer und Schwerhöriger. Monats. $f$. Sprachheilkunde, XVII., 1907. $59 \mathrm{ff}$. 
71. - Zur Frage der gegenseitigen Beziehung zwischen Bauch- und Brustatmung. (Verhandl. d. XX. Congresses f. innere Med.) Monats. f. Sprachheilkunde, XVIII., 1908. 223 ff.

72. Hall, G. Stanley. Educational Problems. New York, IgII, II. $714 \mathrm{pp}$.

73. - A Study of Fears. Amer. Jour. Psychol., VIII., 1897. 147-249.

74. Halle, Ueber Störungen der Atmung bei Stotterern. Monats. f. Sprachheilkunde, X., 1900. 225-236.

75. Hoeprner, T. Psychologisches über Stottern und Sprechen. Zeits. $f$. Psychotherapie u. med, Psychol. III., I9I1. 264-289.

76. _- Stottern als assoziative Aphasie. Zeits. f. Pathopsychol., I., 1912. 449-552.

77. HoRnig, Rein hold. Untersuchungen über das Wesen und Heilung des Stotterns. Monats. f. Sprachheilkunde, XIX., I909. I57$160 ; 183-192$.

- 78. Hunt, JAMES. Stammering and Stuttering. London, 1865. 258 pp.

79. Ibershoff A. E. On the Nature, Causes, and Treatment of Stuttering, etc. Med. Brief. XXXVI., 1908. 202-208.

80. Ives, M. J. Illustrated Phonetics. New York, I909. 132 pp.

81. Janet, Plerre M. F. The Major Symptoms of Hysteria. (Trans.) New York 1907. 345 pp.

82. Jones, ERNest. Zwei interessante Fälle von Versprechen. Zentralbl. f. Psychoanalyse, II., I911. 33-34.

83. Kiesow, F. Versuche mit Mosso's Sphygmomanometer über die durch psychische Erregungen usw. Phil. Stud. XI., I895. 41-60.

84. KOEHLER, W. Akustische Untersuchungen I. Zeits. f. Psychol., LIV., I9IO. 24I-289.

85. Krause, F. Hören und Sprechen. Coethen, I905. Ig8 pp.

86. Kussmaul, Adolf. Die Störungen der Sprache. Vierte Aufl., von H. Gutzmann. Leipzig, 1910. 409 pp.

87. Langfeld, Herbert Sidney. Suppression with Negative Instruction. Psychol. Bull., VII. 1910. 200-208.

88. Langwill H. G. Stammering and Its Treatment. The Practitioner, LXXXV., I910. 568-582.

89. — - A Plea for the Scientific Treatment of Stammering. Rev. Neur. and Psychiatry, V., 1907. 259-280.

90. Laubi, Otтo. Ein Fall von Psychoanalyse bei einem erwachsenen Stotterer. Monats. f. Sprachheilkunde, XXI., I9II. 62-72; III-1 I8.

91. - Psychische Einflüsse bei der Aetiologie und Behandlung des Stotterns. Monats. $f$. Sprachheilkunde, XVII., 1907. $411-418$.

92. LEGEL, O. Die Sprache und ihre Störungen, usw. Potsdam, 1905. $322 \mathrm{pp}$.

93. - Des Kindes Sprachstörungen (Stottern, Stammeln, Lispeln, usw.) und ihre Heilung. Potsdam, 1908. 222 pp.

94. LEROY, E. B. Le langage: essai sur la psychologie normale et pathologique de cette fonction. Paris, I905. 293 pp.

95. LiebmanN, A. Vorlesungen über Sprachstörungen. Berlin, 1906. $132 \mathrm{pp}$.

96. MaAs, Paul. Die Sprache des Kindes und ihre Störungen. Kinderfehler, XV., I909-10. $32 \mathrm{ff}$. 
97. MacCready, E. B. The Relation of Stuttering to Amusia. Jour. Amer. Med. Ass'n., LV., I910. 208 ff.

98. Makuen, G. Hudson. Nomenclature of Defects of Speech. Laryngoscope, XX., I910. I070-1073.

99. - What the Laryngologist may do for the Correction of some of the more common Forms of Speech Defects. Tr. Amer. Laryng., Rhinol., and Otol. Soc., I904-5. 81-88.

100. ㄴ. What Shall We Do with the Stammerer? Internat. Med. Mag., XII., I903. 728-730.

101. An Unusual Form of Stammering. St. Bartholomew Hosp. Report, XLI., 1906. $534 \mathrm{ff}$.

102. The Physiology of Language and its Relation to the Treatment of Stammering. N. Y. Med. Jour., LXXXIV., 1906. I26I-I263.

103. - A Brief History of the Treatment of Stammering. Phil. Med. Jour., XIII, Ig09-10. I9I-197.

104. MARBE, $K$ and SedDig, $M$. Untersuchungen schwingender Flammen. Annalen d. Physik (IV. Folge), XXX., I909. 579-592.

105. Mentz, Paul. Die Wirkung akustischer Sinnersreize auf Puls und Athmung. Phil. Stud., XI., I895. 6I-I24; 37I-393; 563602 .

106. Meumann, E. Die Sprache des Kindes. Zürich, 1903. 82 pp.

107. - Vorlesungen zur Einführung in die experimentelle Pädagogik, II. Aufl. Leipzig, IgI I, I., 726 pp.

108. Mieleche, A. Ueber Stottern als pädagogische Fehler usw. Monats. f. Sprachheilkunde, XVII., Igo7. 364-370.

109. MorT, F. W. The Brain and the Voice in Speech and Song. New York, I9ı. I1 2 pp.

I Io. NAGEL, W. Handbuch der Physiologie des Menschen. Braunschweig, Ig09, IV. 992 pp.

III. NeunofF, J. Das Stottern und andere Sprachfehler. Leipzig, I908. $35 \mathrm{pp}$.

112. NeUmAN , A. Ueber Sprachstörungen und Stottern beim Schreiben. Graz, I893. 94 pp.

I13. Oltuszewski, W. Psychologie und Philosophie der Sprache. Berlin, I90I. 70 pp.

I14. Peterson, F. and Jung, C. G. Psychophysical Investigations with the Galvanometer and Pneumograph in Normal and Insane Individuals. Brain, XXX. 1907. I53-218.

I 5. PilloN, F. La mémoire affective: son importance theoretique et pratique. Rev. phil., LI., I901. I $13-138$.

I16. RADECKI, W. Récherches expérimentelles sur les phénomenes psycho-electriques. Arch. de psychol., XI., I9I I. 209-293.

II7. REICHHARDT, M. Die seelischen Hemmungserscheinungen des Stotterns: Eine pädagogisch-psychologische Studie. Leipzig, I903. 27 pp.

118. Riвot, Tн. The Psychology of the Emotions. (Trans.) New York, I897. $455 \mathrm{pp}$.

II9. Ricksher, C., and Jung, C. G. Galvanic Phenomena and Respiration. Jour. Abn. Psychol., II., I907-8. I89-317.

I20. Rouma, G. Enquête scolaire sur les troubles de la parole chez les écoliers belges. Internat. Archiv f. Schulhygiene, II., I906. I 5 I-I89.

121. Rousselot, P. J. Phonétique expérimentale. Paris, Igo8. $1252 \mathrm{pp}$. 
122. Sarbó, Arthur von. Maladie des Tícs und die damit in Verbindung stehenden Sprachstörungen. Monats. f. Sprachheilkunde, XVII, I907. I78-183; 205-210.

123. - - Die hysterischen Sprachstörungen. Monats. f. Sprachheilkunde, XVII., 1907. 97-106; 140-149.

124. Schaefer, E. A. Text-Book of Physiology. N. Y., 1898, II, 1365 pp.

125. SCRIPTURE, E. W. The Treatment of Negligent Speech by the General Practitioner. Med. Rec., LXXIV., I908. 257-260.

126. - The Treatment of Stuttering. Med. Rec., LXXI., 1907. $771 \mathrm{ff}$.

127. - The Treatment of Hyperphonia (Stuttering and Stammering) by the General Practitioner. Med. Rcc., LXXIII., I908. 480-481.

128. - Penmanship Stuttering. Jour. Amer. Med. Ass'n., LII., I909. I480-148I.

129. - - Stammering: Its Nature and Treatment. Synopsis of Lecture before Boston Soc. of Neurol, and Psychiatry. - Boston, May Io, I9I2.

130. Sherrington, C. S. The Integrative Action of the Nervous System. New York, 1906. 4II pp.

131. Sidis, B. The Galvanic Phenomena. Psychol. Bull. VII., 1910. 32I-322.

132. - The Nature and Causation of the Galvanic Phenomena. Psychol. Rev., XVII., I9I0. 19-36.

133. Sidis, B., and Kalmus, H. T. The Study of Galvanometric Deflections. Psychol. Rev., XV., 1908. 391-396.

134. Smith, Theodate L. On Muscular Memory. Amer. Jour. Psychol., VII., I895-6. 453-490.

135. Starch, D. Mental Processes and Concomitant Galvanometric Changes. Psychol. Rev., XVII., igio. 19-36.

136. Stekel, William. Nervöse Angszustände und ihre Behandlung. II. Aufl. Berlin, 1912. $448 \mathrm{pp}$.

137. Тнимв, A. Die experimentelle Psychologie in Dienste der Sprachwissenschaft. Marburg, 1909. I3 pp.

138. Titchener, E. B. A Text-Book of Psychology. New York, I9II. 565 pp.

139. Tomor, ERnest. Die Rolle der Muskeln beim Denken. Archiv. f. d. ges Psychol., XVII., I9I0. 362-366.

140. VAN DER TORREN, J. Das normale Verhören, Versprechen, Verlesen, und Verschreiben, nebst ihren Beziehungen zur Pathologie. Zeits. f. d. ges. Neurol. u. Psychiatrie, IV., Igri-Igr2. $657-678$.

141. Town, Clara Harrison. Congenital Aphasia. Psychol. Clin., V., 1911. 167-179.

142. Troem Ner, E. Zur Pathogenese und Therapie des Stotterns. Wien. klin. ther. Woch. XII., 1905. I89-196; 219-223.

143. Ursachen und Handlung des Stotterns. Deutsche Med. Woch., XXX., 1904. I336 ff.

144. Varendonck, J. Phobies d'enfants. Rev. Psychol., III., I9Io. 5-45.

145. Wells, F. L., and Forbes, A. On Certain Electrical Processes in the Human Body and Their Relation to Emotional Reactions. Archiz'es of Psychol., II., No. 16, I9I1. I-39.

146. Wund, William. Völkerpsychologie: Die Sprache. Berlin, I9II. $695 \mathrm{pp}$. 
147. Wyllie, John. The Disorders of Speech. Edinburgh, I894. 148. ZAHN, TH. Ueber die Ursachen des Stotterns. Monats. $f$. Sprachheilkunde. XXI., 19II. I 49-158.

149. ZoNEFF, $P$, and MEUManN, E. Ueber Begleiterscheinungen psychischer Vorgänge in Athem und Puls. Phil. Stud., XVIII., I902. I-II3.

150. ZUND-BURGUET, A. Etude physiologique et pratique sur les troubles externes ou méchaniques de la parole. Arch. Internat. de Laryng., XIX. I905. 486; 825; XX., I906, 856 ff.; XXI., 1907. $186 \mathrm{ff}$.

(Since the completion of this study two books have appeared that should be added to the above list.)

I5I. Bluemer, C. S. Stammering and Cognate Defects of Speech. New York, igr3. 2 v.

152. SCRIPTURE, E. W. Stuttering and Lisping. NeW York, I9I2. 25 I Pp. 

X. Illustrative Plates

Typical records are here reproduced to illustrate certain physiological phenomena that accompany stuttering, not all of which are amenable to detailed description or tabulation. The records read from left to right; the time is recorded in seconds. In all the breathing records the amount of inhalation is registered by the downward movement of the stylus, that of exhalation is indicated by the upward movement; the duration of both inhalation and exhalation is measured by the extent of the movement in the horizontal direction. By comparing all points of each curve that lie on a line drawn perpendicular to the line of movement of the drum the temporal relations of the different phases of the processes recorded can be determined. 
Plate A gives two records taken at different intervals and showing the thoracic curve above and the abdominal curve below in each case. Below the abdominal curve of each record, the registration of the microphone is shown by the up and down movements of the stylus. The abnormality of this record is shown in the arhythmic character of the breathing curve and also in the scantiness of the voice record.

Plate B is reproduced for the purpose of comparing it with record $\mathrm{C}$ following to illustrate the possibility of both normal and abnormal speaking in the same subject. The perpendicular lines are drawn to show the method of comparing the several registrations. In this record the subject is stuttering, while in record $\mathrm{C}$ he is speaking normally. Note the tendency to attempt to speak when the lungs are empty, and even during the exhalation period.

Plate $C$ is to be compared with record $B$. The regular succession of inhalation by exhalation, the short inhalation and the long exhalation period, also the complete utilization of the exhalation period by vocalization, as shown by the microphone record, are the chief points of difference between the two.

Plate D gives a plethysmogram showing simultaneously the volumetric changes and the heart-rate, also the thoracic and the abdominal breathing curves. Sudden breathing and vaso-motor changes are seen to mark the period of the beginning of speech.

Plate $E$ gives the same as record $D$ with the addition of a voice record. In addition to the marked irregularities of the breathing curve the steady rise of the plethysmographic curve is to be noted. The full extent of this rise is greater than could be shown in the length of the reproduction here given.

Plate $F$ shows the tracings that followed the deflections of the galvanometer during the stuttering of two subjects $H$. $A$. (top), and $A$. N. (bottom). A. $N$. is a much worse stutterer than $H$. $A$., and there is also found in his case a much wider deflection. It is seen that $A$. $N$.'s curve reaches a maximum and then moves gradually in the direction of relaxation, or upward.

Plate $G$ shows the galvanometer deflections obtained from the same subject when reading under different conditions. In the first registration, $A$. $B$., the subject, is reading alone and stuttering. In the second registration he is reading with the experimenter, $\alpha$ to $\beta$, without stuttering, and also relaxing, $\beta$ to $\gamma$. The introspective report of this record showed the presence of "strain," and "lack of confidence" in the first registration. and "less emotional excitement" in the second. 


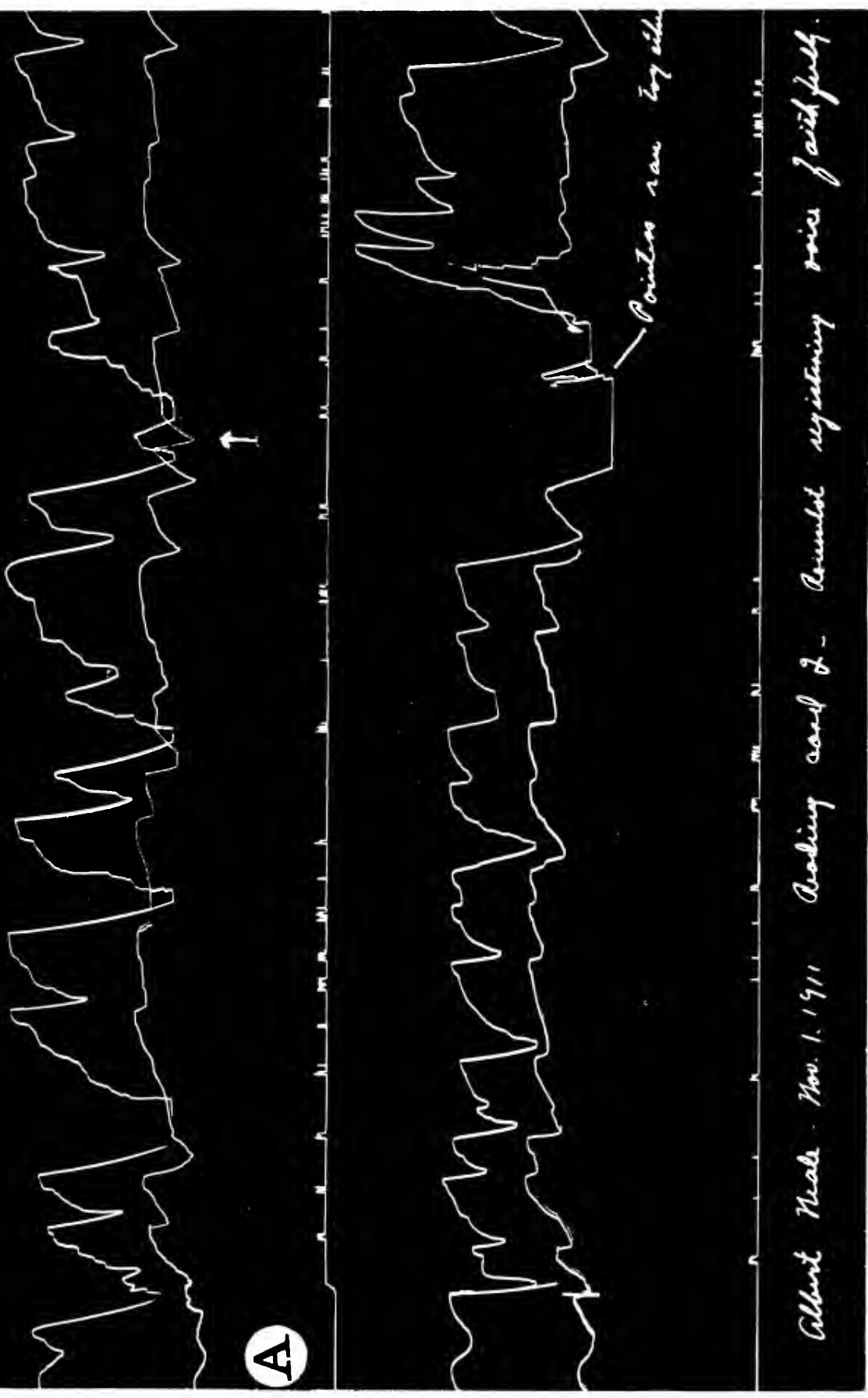





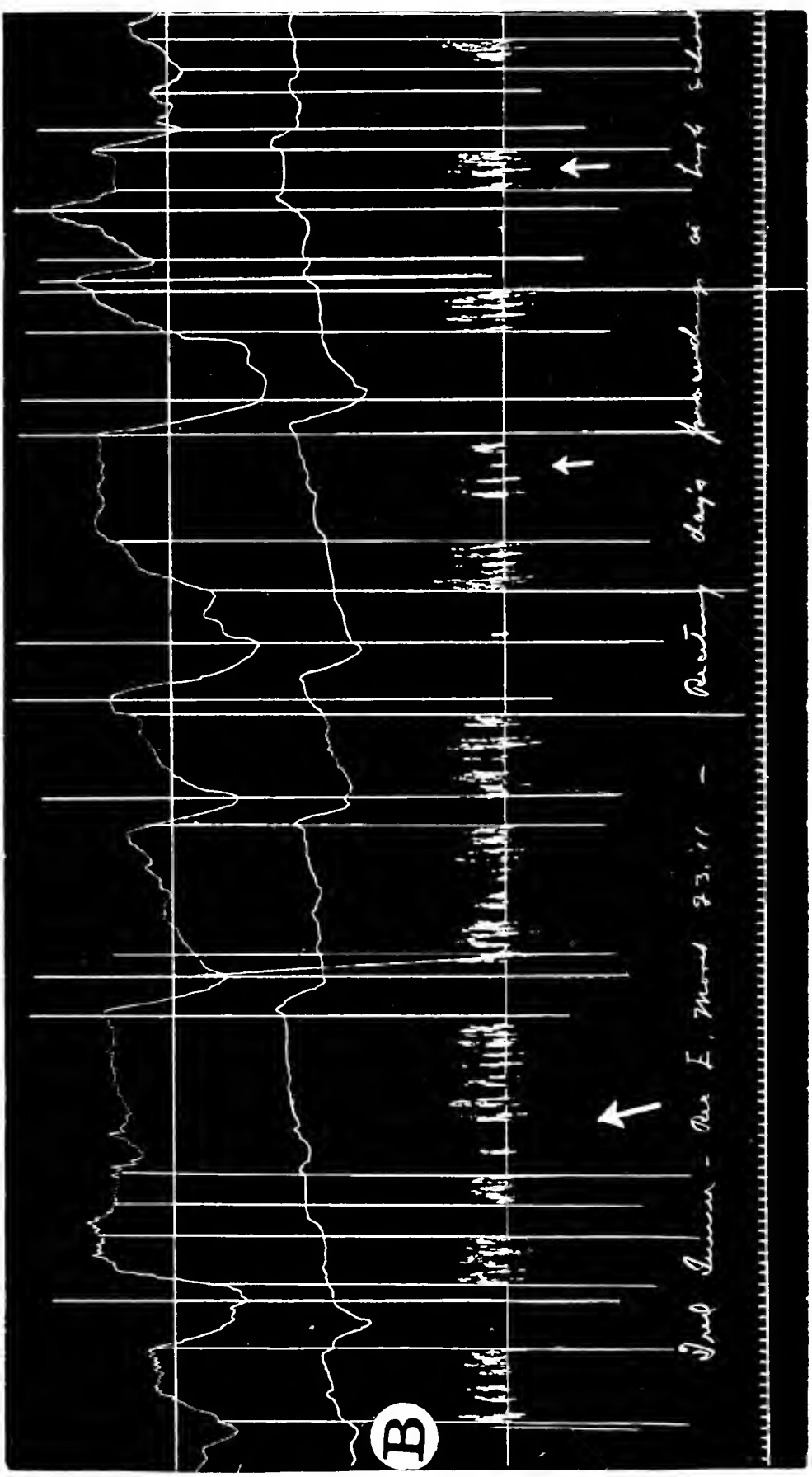





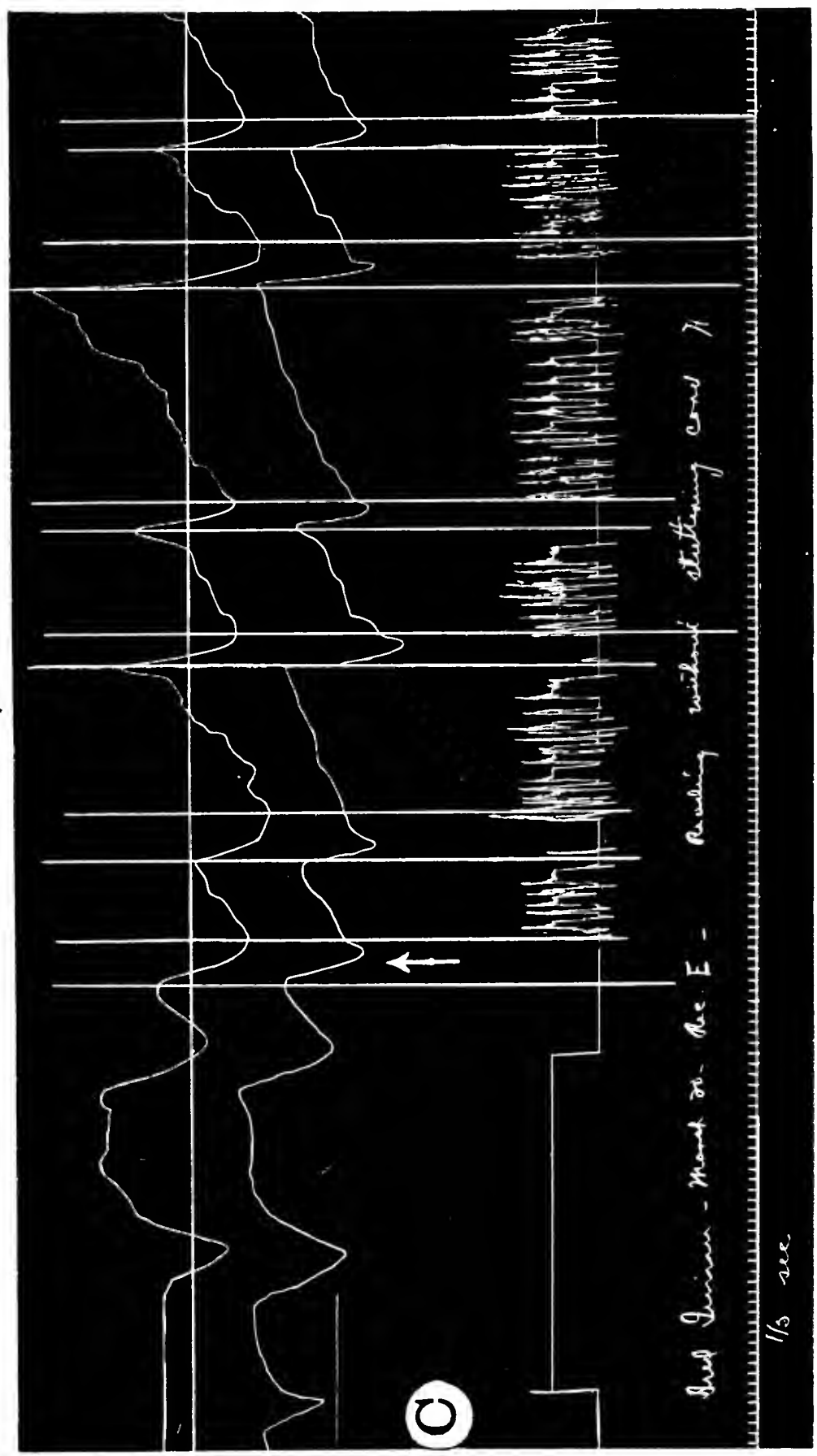





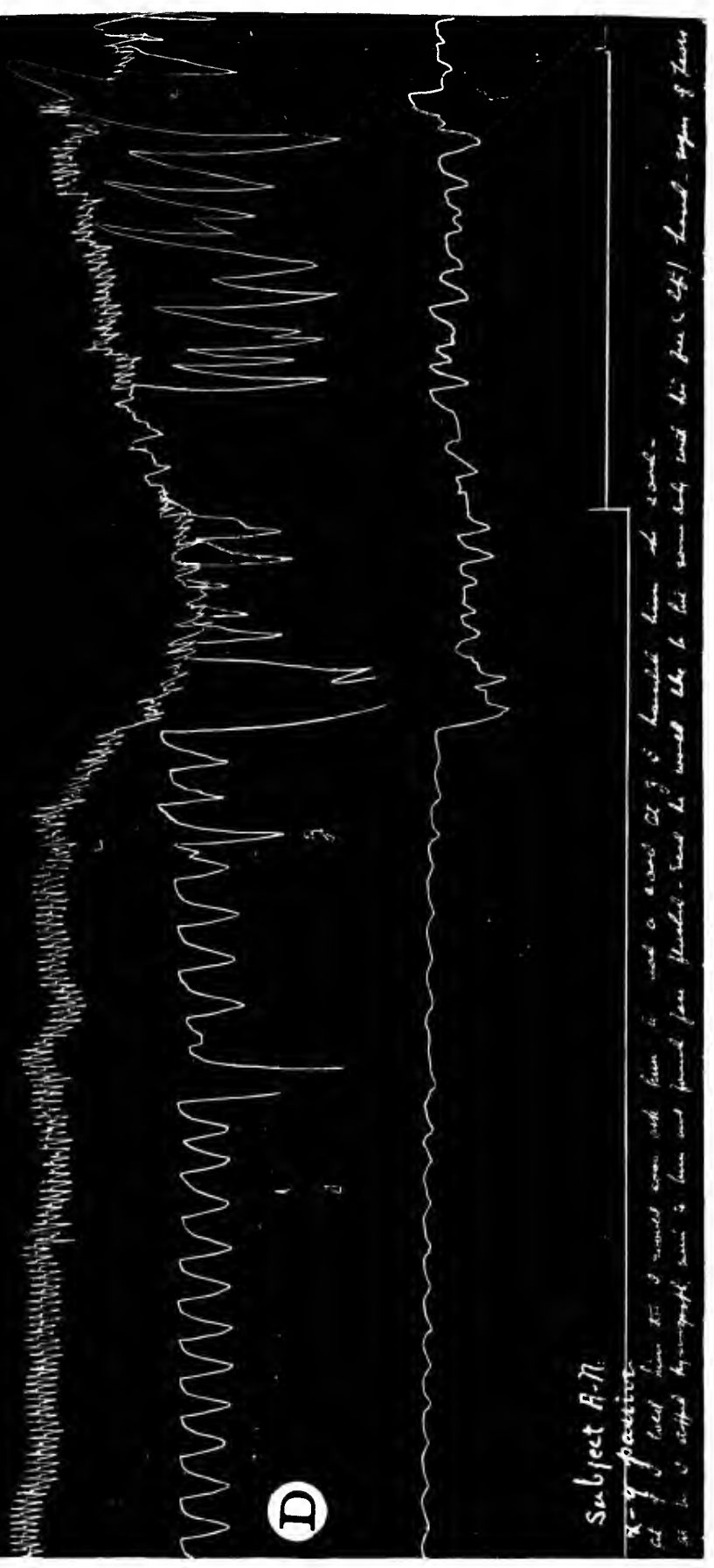





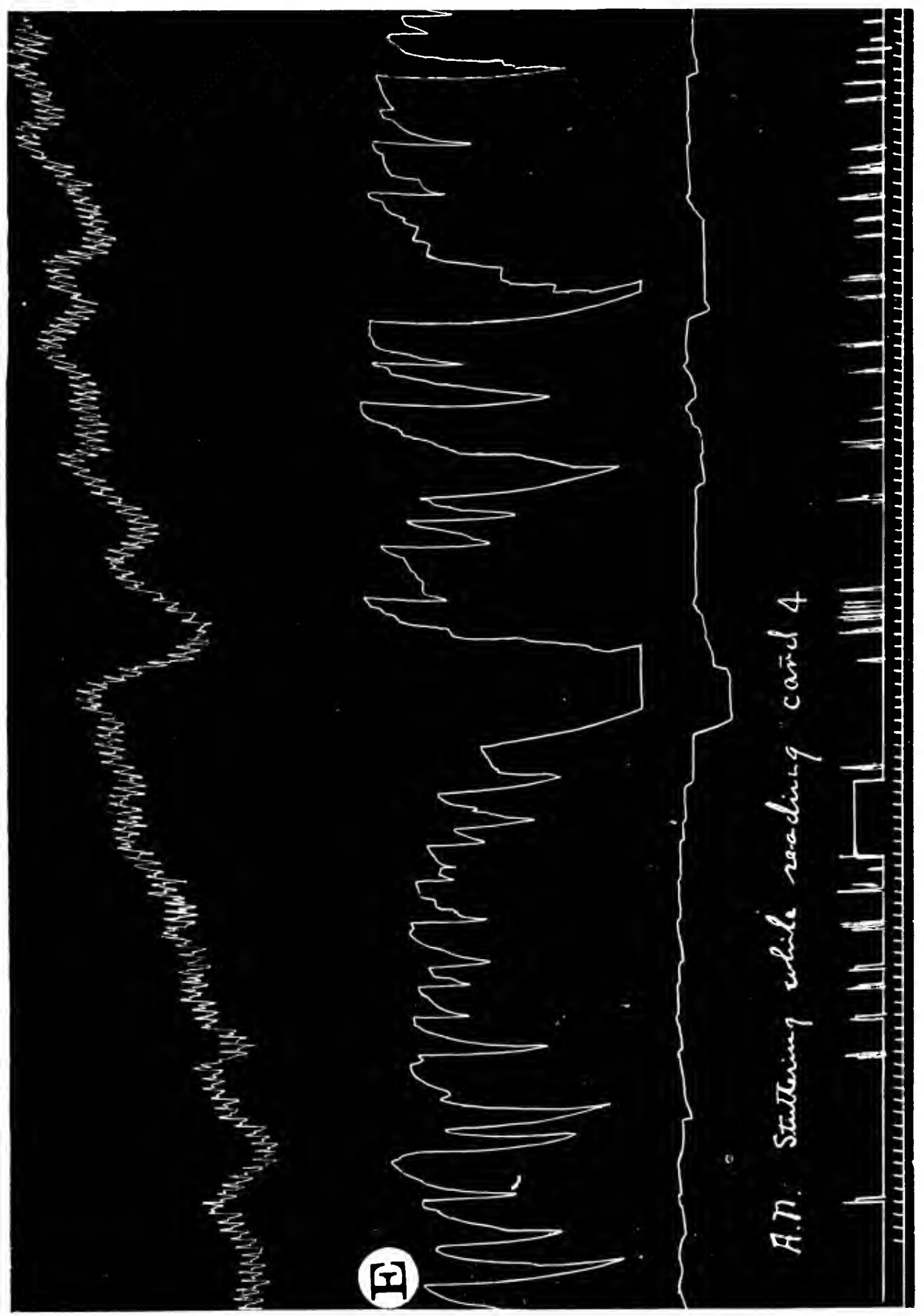





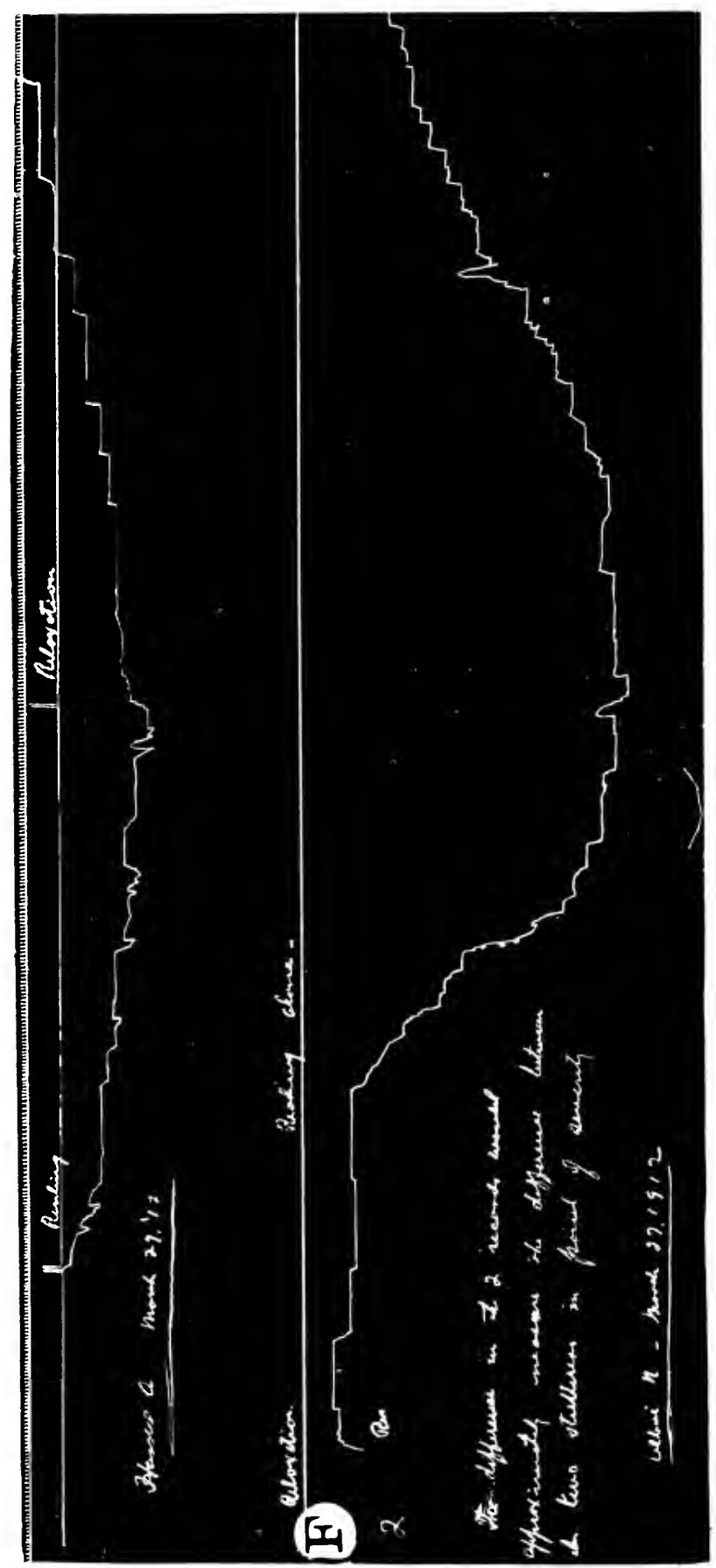





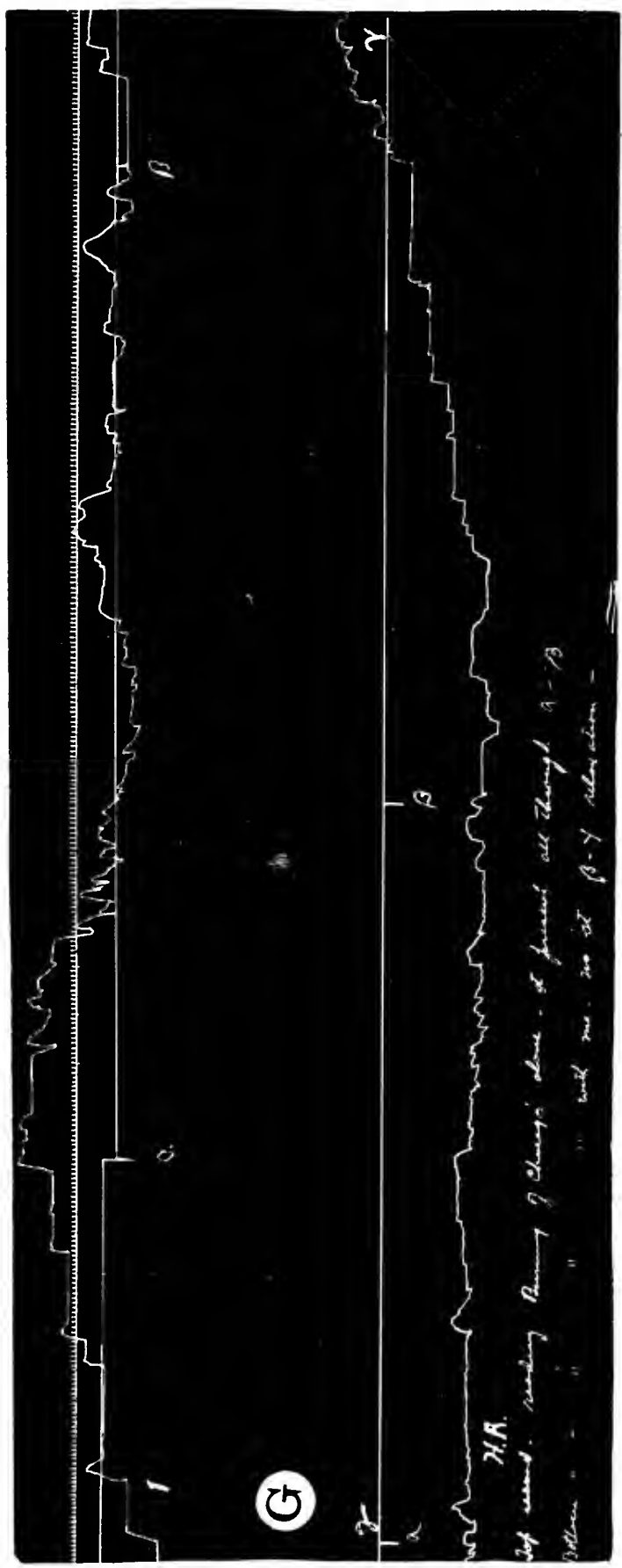




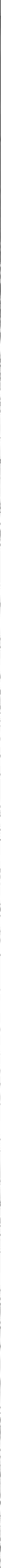




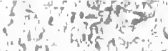

$$
\begin{aligned}
& \text { in } \\
& \text { a } 34
\end{aligned}
$$

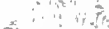

$$
\begin{aligned}
& x \div
\end{aligned}
$$

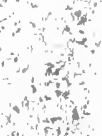

$$
\begin{aligned}
& \therefore \text { ar } \\
& \operatorname{lin}^{2} \\
& \text { in } \\
& \text { and } \\
& \text { A the } \\
& \text { (4) } \\
& \therefore \rightarrow+n \\
& \because \quad \therefore \quad \therefore-1 \\
& \text { i. } \\
& \left\{\begin{array}{c}
2 \\
1
\end{array}\right. \\
& \text { a. } \\
& \text { orition }
\end{aligned}
$$

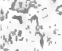

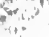

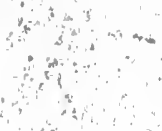

$$
\begin{aligned}
& \text { s. } \\
& 7 \text {, }
\end{aligned}
$$

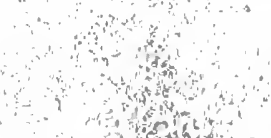

$$
\begin{aligned}
& \therefore \text { is } \rightarrow \\
& \therefore \text { of } \\
& \text { a }
\end{aligned}
$$

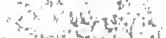

$$
\begin{aligned}
& \text { on } 14 \text { an } \\
& \text { - } \\
& \text { End }
\end{aligned}
$$
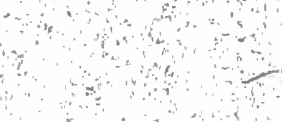

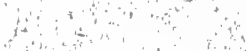

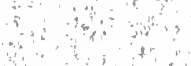

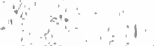

$$
\begin{aligned}
& \begin{array}{ccc}
5 \\
3
\end{array} \\
& \text { a }
\end{aligned}
$$
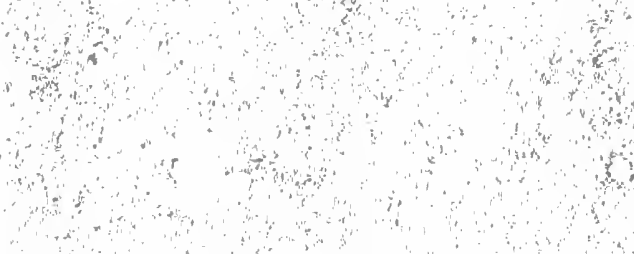


\section{DAY USE}

\section{RETURN TO DESK FROM WHICH BORROWED}

\section{BIOLOEY LBBRARY}

This book is due on the last date stamped below, or on the date to which renewed.

Renewed books are subject to immediate recall.

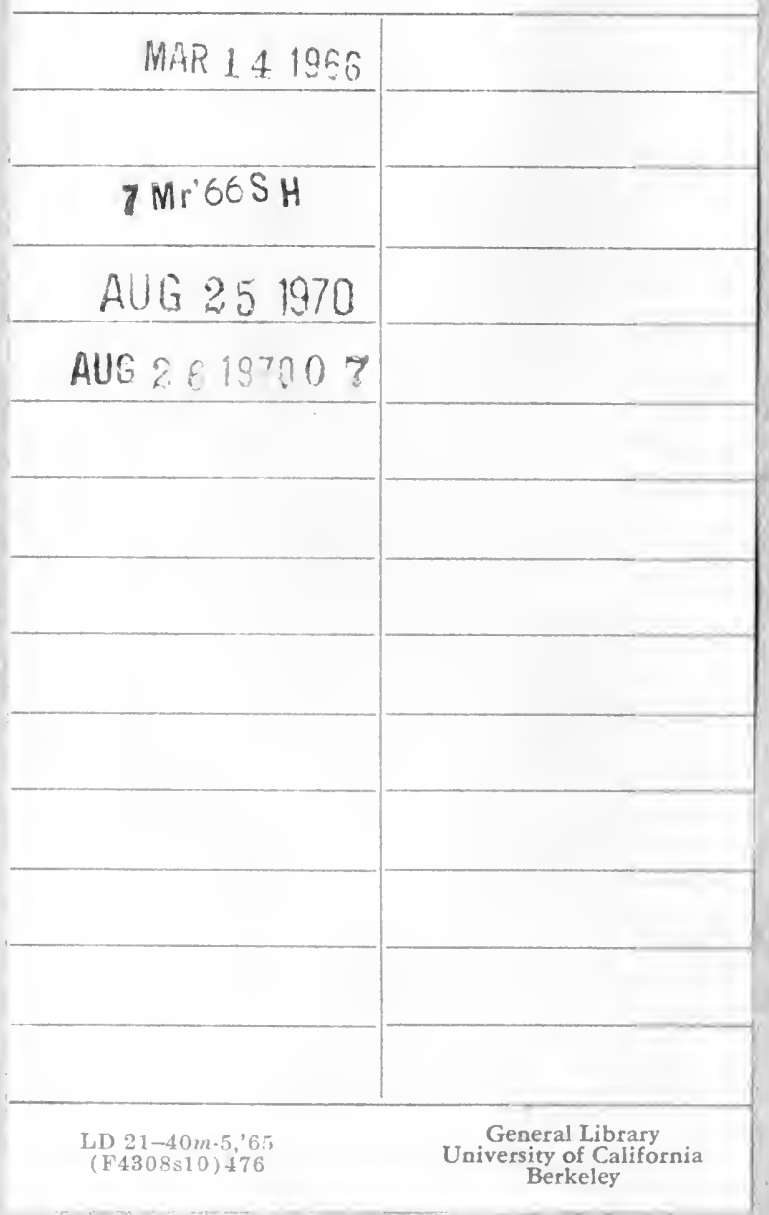





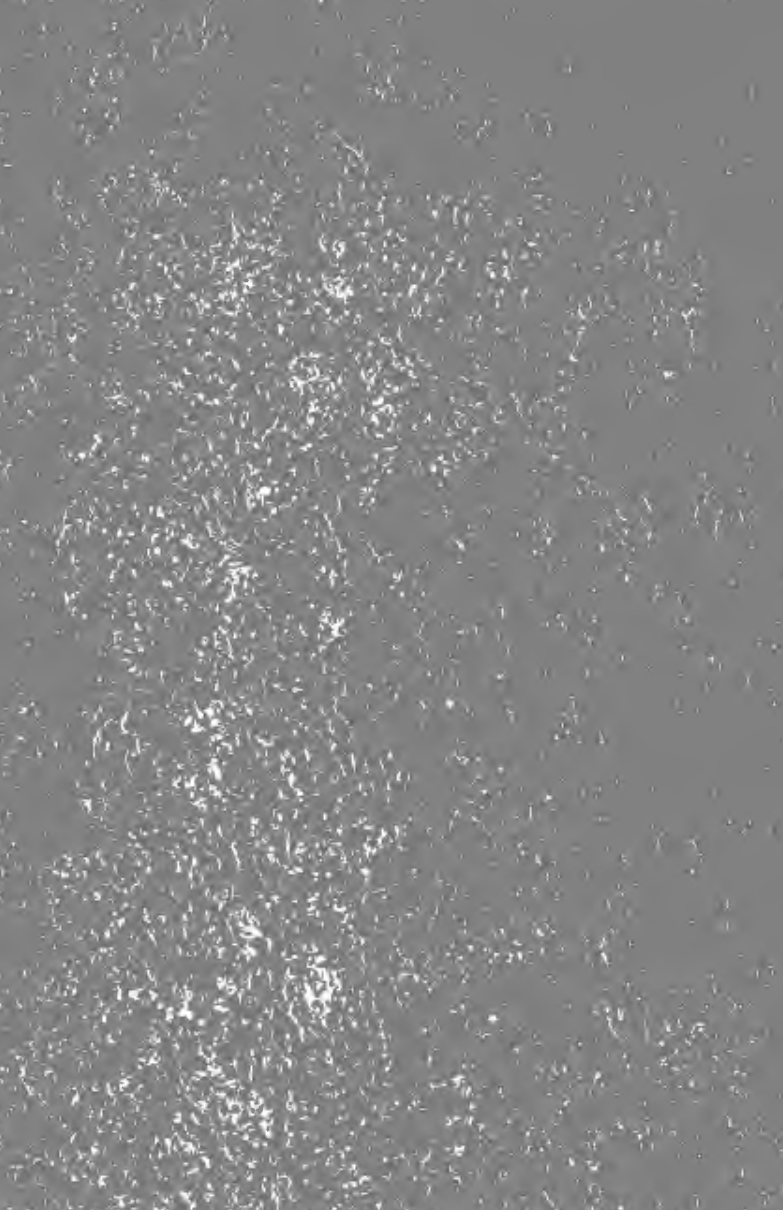
$\frac{1}{4}$

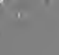

